\title{
A Simple Auction Mechanism for the Optimal Allocation of the Commons
}

\author{
Juan-Pablo Montero*
}

July 1, 2007

\begin{abstract}
Efficient regulation of the commons requires information about the regulated firms that is rarely available to regulators (e.g., cost of pollution abatement). This paper proposes a simple mechanism that implements the first-best for any number of firms: a uniform price sealed-bid auction of an endogenous number of (transferable) licenses with a fraction of the auction revenues given back to firms. Paybacks, which rapidly decrease with the number of firms, are such that truth-telling is a dominant strategy regardless of whether firms behave non-cooperatively or collusively. The mechanism also provides firms with incentives to invest in socially optimal R\&D (JEL D44, D62, D82, Q28)
\end{abstract}

Regulatory authorities generally find that part of the information they need for implementing an efficient regulation is in the hands of those who are to be regulated. Regulating externalities such as access to common resources (e.g., clean air, water streams, fisheries, etc.) is a good example. Environmental regulators, for example, know little about firms' pollution abatement costs, so without communicating with firms they would be unable to establish the efficient level of pollution. A number of mechanisms have been proposed for inducing firms to reveal their private information, but for different reasons,

*Department of Economics, Pontificia Universidad Católica de Chile, Vicuña Mackenna 4860, Santiago, Chile, and MIT's Center for Energy and Environmental Policy Research (jmontero@faceapuc.cl). I would like to thank Vincent Crawford (the Editor), Tony Creane, Larry Goulder, Evan Kwerel, Matti Liski, Marty Weitzman, three anonymous referees, seminar participants at the ASSA Meetings (Chicago 2007), Harvard University, Helsinki School of Economics, Texas A\&M University, University of Maryland, University of Massachusetts-Amherst, Universidade de Vigo and Universidad Alberto Hurtado, and specially Bill Hogan for many reactions and comments. Most part of the article was written while I was visiting Harvard's Kennedy School of Government (KSG) under a Repsol YPF-KSG Research Fellowship. Financial support from Fondecyt (1070982) and Instituto Milenio SCI (P05-004F) is also gratefully acknowledged. All errors and omissions are mine. 
these mechanisms have been of limited use. In this paper, I propose a simple mechanism that implements the first-best for any number of incompletely-informed firms: a uniform price sealed-bid auction of an endogenous number of (transferable) licenses with a fraction of the auction revenues given back to firms. ${ }^{1}$ Paybacks, which rapidly decrease with the number of firms, are such that truth-telling is a dominant strategy regardless of whether firms behave non-cooperatively or collusively.

Following Martin L. Weitzman (1974), several authors have looked for ways in which to improve upon his fixed tax or license scheme. Marc J. Roberts and Michael Spence's (1976) hybrid tax/license scheme can in principle implement the first-best when there is an infinitely large number of firms and the regulator is free to impose a tax schedule (as opposed to a fixed tax) and issue a continuum of license types, with each type clearing at a different price. Building also upon the assumption of perfect competition in the license market, Evan Kwerel (1977) develops a simpler subsidy/license scheme that implements the first-best in Nash equilibrium. Relaxing the perfect competition assumption and allowing for pollutant differentiation, Partha Dasgupta, Peter Hammond and Eric Maskin (1980) propose a tax scheme obtained from an adaptation of the Vickrey-Clarke-Groves (VCG) mechanism, which has the advantage of implementing the first-best in dominant strategies. $^{2}$ Jae-Cheol Kim and Ki-Bok Chang (1993) present a tax/subsidy scheme with a payoff close to that of Dasgupta-Hammond-Maskin (DHM) in which each firm pays for its residual damage. Although payments are not exactly the same because of differences in the definition of residual damage, the main difference with DHM is that Kim and Chang (1993) is not implemented in dominant strategies; it requieres each firm to correctly anticipate the (Nash equilibrium) level of pollution of the remaining firms, i.e., it requires complete information by firms.

The assumption of completely-informed firms is also found in more recent mechanisms. Hal R. Varian's (1994) advance a multistage price-based mechanism in which each firm announces Pigouvian taxes for all firms including itself (taxes do not need be equal). The first-best is implemented in subgame-perfect Nash equilibrium. John Duggan and Joanne Roberts (2002) propose instead a quantity-based scheme in which each firm chooses the number of licenses for itself and for its "neighbor", but unlike Varian (1994), it implements the first-best in Nash equilibrium. ${ }^{3}$

With the exception of Kwerel (1977), all these first-best mechanisms depart from the regulatory approaches we observe in practice (e.g., Robert N. Stavins, 2003). ${ }^{4} \mathrm{Kw}-$

\footnotetext{
${ }^{1}$ Licenses are generally refered to as permits or allowances in water and air pollution control, as rights in water supply management and as quotas in fisheries management. In this paper, I will use the term license throughout.

${ }^{2}$ See also Daniel F. Spulber (1988) for consideration of budget constraints and output interactions.

${ }^{3}$ See also Marcelo Caffera and Juan Dubra's (2006) industry-specific emission standard mechanism.

${ }^{4}$ It is beyond the scope of the paper to discuss the (political economy and/or other) reasons for this
} 
erel's scheme, on the other hand, is quite simple: the regulator issues a fixed number of transferable licenses and establishes a subsidy per license to be paid to any firm holding licenses in excess of its emissions (in equilibrium, the subsidy is not used). Both the total number of licenses and the subsidy level are calculated on the basis of the information provided by firms. Unfortunately, the scheme presents some limitations regardless of how licenses are allocated to firms. ${ }^{5}$ If licenses are allocated for free (i.e., grandfathered), it can be shown (Proposition 1) that firms have incentives not to reveal their true demand functions but to over-report their demand for licenses to the maximum extent possible.

If, on the other hand, the total number of licenses are allocated via a uniform-price auction in which each firm bids a demand schedule indicating the number of licenses willing to purchase at any given price, there is no guarantee that firms will reach the competitive outcome (Paul Milgrom, 2004). As first recognized by Robert Wilson (1979) in his pioneer "auctions of shares" article, even when there is a large number of bidders, uniform price auctions can exhibit Nash equilibria with prices far below the competitive price (the price that would prevail if all bidders submit their true demand curves). The reason for this is that uniform pricing creates strong incentives for bidders to (noncooperatively) shade their bids at the auction in order to depress the price they pay for their inframarginal units. Therefore, anticipating a low-price equilibrium at the auction, firms may find it again profitable to over-report their demand functions to the regulator prior to the auction in order to induce the regulator to auction a large number of licenses that can then be sold back to the government at a price higher than the auction clearing price.

Different solutions have been advanced in dealing with this low-price equilibria phenomenon. One radical solution is to give up the uniform-price format altogether and opt for a discriminatory-price format (e.g., William Vickrey, 1961; Lawrence M. Ausubel, 2004). But within the uniform-price format, different authors have also been looking for ways in which changing auction rules could eliminate underpricing. Ilan Kremer and Kjell G. Nyborg (2004), for example, propose changing the allocation rule (i.e., the way the asset is divided when there is excess demand at the clearing price) from the

to be the case, but it seems reasonable to depart from mechanisms that rely on complete information by firms and/or perfect competition when such assumptions are unlikely to hold. Evidence of significant information asymmetries across firms facing a commons problem is provided, for example, by Steven N. Wiggins and Gary D. Libecap (1985).

${ }^{5}$ Kwerel (1977) is never explicit on the allocation of licenses other than assuming that firms pay a uniform price for all licenses purchased. Besides, there is not much we can infer from the firm's cost minimizing problems laid out in pages 596 and 597 because of the price-taking behavior (i.e., any grandfathered allocation can be omitted from the minimization problem since it is a lump-sum transfer with no effect on the firm's abatement decision). It is also not obvious how to adapt Kwerel's scheme to the case of pollution differentiation. 
usual marginal pro rata tie-breaking rule to a total pro rata rule. ${ }^{6}$ More recently, David McAdams (2005) eliminates underpricing by letting the auctioneer not to commit to a fixed quantity and reserve price ex-ante. Bidders only learn about the total quantity sold by the auctioneer once the auction is concluded.

In this paper I propose a mechanism that builds upon a conventional uniform price sealed-bid auction but in order to guarantee the efficient outcome, I introduce two key ingredients. First, I let the total number of licenses be endogenous to the demand schedules submitted by firms. This is a most natural thing to do in our context because the benevolent regulator is clueless about the efficient number of licenses to be allocated before communicating with firms. But unlike in McAdams (2005), this "flexible supply" feature by itself does not fully solve the underpricing problem. ${ }^{7}$ Hence, I introduce a second ingredient: rebates or paybacks. Part of the auction revenues are returned to firms not as lump sum transfers but in a way that firms would have incentives to bid truthfully. While rebates may seem odd in other contexts, ${ }^{8}$ they are not new in existing auctions for "protecting the commons". ${ }^{9}$ Furthermore, an auction with paybacks seem to be a natural point of departure for any license-type regulatory proposal given the mixed experience with allocating licenses (grandfather allocation vs. auction allocation) that is observed in existing programs across a variety of areas including air-pollution control, water supply management and fisheries management (Tom Tietenberg, 2003). ${ }^{10}$

The two ingredients - endogenous supply of licenses and paybacks - enter into the uniform-price format in a way that the resulting auction mechanism is both ex-post efficient and strategy-proof (i.e., telling the truth is a dominant strategy). ${ }^{11}$ The supply

\footnotetext{
${ }^{6}$ For the change in the allocation rule to have an effect on clearing prices, bidders must be allowed to submit discountinuous demand schedules, which, by construction, is not possible in Wilson (1979). But unlike in Kremer and Nyborg (2004) where bidders have a constant valuation for the asset, in our context this allocation rule change is of little help because bidders do have fairly continuos downward sloping demand curves.

${ }^{7}$ It only works in the limit, when there is an infinitely large number of firms so that paybacks are virtually zero. Part of the reason why "flexible supply" is not sufficient is because I work with a very different set of assumptions than McAdams (2005). I let firms to be asymmetric, to have downward sloping demand curves and to know nothing about other firms' characteristics. In addition, my auctioneer's objective function is not to maximize revenues but social welfare.

${ }^{8}$ Not surprisingly they are absent in recent books by Milgrom (2004) and Paul Klemperer (2004).

${ }^{9}$ See, for example, the US EPA auction for sulfur dioxide allowances (Paul L. Joskow et al., 1998). See also Hans Gersbach and Till Requate (2004).

${ }^{10}$ See also Peter Cramton and Suzi Kerr (2002) for related arguments.

${ }^{11}$ This result may look surprising at first, given the result of Jerry R. Green and Jean-Jacques Laffont (1979) that there is no social choice function that is strategy-proof and ex-post efficient. That result relies crucially on the fact that the type of all the players is not known. In this paper, however, the type of one player, the benevolent regulator, is known, that is, the "mechanism designer" knows the regulator's loss function from allocating licenses to firms (e.g., the pollution damage function). Given that, it is well known for quasi-linear environments that using the known player as a money sink or source one can design an ex-post efficient and strategy-proof mechanism (Andreu Mas-Colell et al., 1995, pp.
} 
curve of licenses reflects the cost to society (other than firms) from allocating these licenses to firms. Paybacks, on the other hand, are such that the total payment for licenses of each firm is exactly equal to the "damage" it exerts upon all the other agents (i.e., other regulated firms and the rest of society). For example, in the case of a single polluting firm, the total payment faced by the firm is equal to the pollution damage $D(l)$, where $l$ is the number of licenses/pollution allocated to the firm at the auction. In the case of multiple firms, the total payment faced by firm $i$ is equal to its residual damage $D_{i}\left(l_{i}\right)$, which involves both its pecuniary externality imposed upon other competing bidders (i.e., regulated firms) and its residual pollution externality. The residual damage function $D_{i}\left(l_{i}\right)$ is computed by substracting from the supply curve $D^{\prime}(l)$ all other firms' bids, so it is independent of firm $i$ 's bid.

The auction mechanism follows a VCG payoff rule in that it makes each firm to pay exactly for the externality it imposes on the other agents. ${ }^{12}$ Nevertheless, payoffs and allocations are computed differently than in the VCG tax mechanism of DHM. Because of the structural differences the two mechanisms differ in at least two important ways. First, the DHM mechanism, unlike the auction mechanism, fails to allocate resources efficiently across firms when the aggregate supply of licenses is fixed. This is because each individual firm is no longer "pivotal" in DHM in the sense that its report does not affect the aggregate supply. This is an important distinction because in many commons problems the aggregate supply is likely to be fixed, either because of the presence of some genuine threshold or because the auctioneer/regulator has no control over the aggregate supply. ${ }^{13}$ Second, tax schedules in DHM are by definition non-transferable, so any collusive effort distorts the first-best allocation in that it must be based on some over-reporting of types. ${ }^{14}$ In contrast, in the auction mechanism is collusive optimum for cartel firms to implement the first-best. Since licenses are by definition fully transferable, cartel firms mimic a single entity at the auction and then proceed with efficient license transfers among themselves.

The article is organized as follows. Section I presents the modelling assumptions and a brief discussion of Kwerel's scheme. Section II describes the auction mechanism; first for a single firm and then for multiple firms. Section III describes several properties of the mechanism including its relationship to the DHM mechanism. Section IV looks at how

\footnotetext{
876-82).

${ }^{12}$ It is also payoff equivalent to the discriminatory auctions of Vickrey (1961) and Ausubel (2004).

${ }^{13}$ For the same reasons, DHM may also fail to deliver the first-best when demand curves exhibit flat portions. If a firm believes that the equilibrium allocation is likely to lie on a perfectly elastic portion of the aggregate demand curve irrespective of its report, it would rather submit a null report.

${ }^{14}$ Note that if the constant terms in DHM tax schedules are made equal to zero, collusion is no longer a concern but individual payments of the (now Groves) mechanism would suffer a substantial increase - the full social cost.
} 
the mechanism performs under collusive behavior. Section V concludes. The Appendix contains the proofs to all propositions.

\section{The Model}

To facilitate the exposition I will develop the model for the case of a classical pollution externality (which would correspond to an auction of shares with variable supply). But it is worth emphasizing that the model readily extends to other commons problems including those in which licenses are firm-specific (e.g., if there is pollution differentiation) and where firms impose (private) externalities on each other. ${ }^{15}$

\section{A. Notation and First-Best Allocation}

Consider $n \geq 1$ firms $(i=1, \ldots, n)$ to be regulated. All firms are assumed to have inverse demand functions for pollution of the form $P_{i}\left(x_{i}\right)$ with $P_{i}^{\prime}\left(x_{i}\right)<0$, where $x_{i}$ is firm $i$ 's pollution level that is accurately monitored by the regulator (In some cases I will work with the demand function, which is denoted by $X_{i}(p)$ with $X_{i}^{\prime}(p)<0$, where $p$ is the price of pollution). Function $P_{i}(\cdot)$ is only known by firm $i$, neither by the regulator nor by the other firms. The aggregate demand curve for pollution is denoted by $P(x)$, where $x=\sum_{i=1}^{n} x_{i}$ is total pollution. The social damage caused by pollution $x$ is $D(x)$ with $D(0)=0, D^{\prime}(x)>0$ and $D^{\prime \prime}(x) \geq 0$. $D^{\prime}(x)$ can be interpreted more generally as the regulator's supply function for licenses $S(p)$, where $D^{\prime}(S(p))=p$. We may want to assume that $D(x)$ is publicly known but it is actually not necessary.

In the absence of regulation firm $i$ would emit $x_{i}^{0}$, where $P_{i}\left(x_{i}^{0}\right)=0$. Hence, firm $i$ 's

cost of reducing emissions from $x_{i}^{0}$ to some level $x_{i}<x_{i}^{0}$ is $C_{i}\left(x_{i}\right)=\int_{x_{i}}^{x_{i}^{0}} P_{i}(z) d z$ (note that $\left.-C_{i}^{\prime}\left(x_{i}\right) \equiv P_{i}\left(x_{i}\right)\right)$, and the minimum total cost of achieving pollution level $x<x^{0}$ is $C(x)=\int_{x}^{x^{0}} P(z) d z$.

The regulator's objective is to minimize the sum of clean-up costs and damages from pollution, i.e., $C(x)+D(x)$. Therefore, the socially optimal or first-best pollution level $x^{*}<x^{0}$ satisfies

$$
P\left(x^{*}\right)=D^{\prime}\left(x^{*}\right)=P_{i}\left(x_{i}^{*}\right) \text { for all } i=1, \ldots, n
$$

But the regulator cannot directly implement the first-best allocation because he does not know the demand functions $P_{i}(\cdot)$. He must then look for mechanisms in which it is in the firms' best interest to communicate their private information to him. Kwerel (1977) advances one of such mechanisms for the case in which there are many firms.

\section{B. Kwerel's Scheme}

\footnotetext{
${ }^{15}$ Formal analysis of these extensions are found in Montero (2007).
} 
To appreciate the workings of my auction scheme it is useful to start by understanding firms' incentives under Kwerel's scheme. This latter proves to be interesting in itself because, as we shall see below, the scheme may not work as intended.

Kwerel is a two-stage mechanism based on the combination of two instruments: an allocation of a total of $l$ transferable licenses and a subsidy of $s$ per license to be paid to any firm holding licenses in excess of its emissions. In the first (or reporting) stage, the regulator asks firms to report their demand curves (i.e., types) after they are informed that the parameters $l$ are $s$ are to be set according to

$$
s=\hat{P}(l)=D^{\prime}(l)
$$

where $\hat{P}(\cdot)$ is the aggregate demand curve built upon individual reports $\hat{P}_{i}\left(x_{i}\right)$.

In the second (or allocation) stage, the $l$ licenses are allocated to firms (it is not specified whether the licenses are allocated via a uniform-price auction or for free). Assuming that the market for licenses is perfectly competitive, it must hold in equilibrium that $P_{i}\left(x_{i}\right) \equiv-C_{i}^{\prime}\left(x_{i}\right)=p$ and $x_{i}=l_{i}$ for all $i=1, \ldots, n$, where $p$ denote the market price of licenses. Firms equate marginal abatement costs to the market price and keep a number of licenses just to cover their emissions. Kwerel argues that this simple scheme induces each firm $i$ to report its true demand curve $P_{i}(\cdot)$ as long as it believes all other firms are telling the truth. In other words, truth-telling is a (Bayesian) Nash equilibrium.

Kwerel's argument can be easily explained with the aid of Figure 1. Figure 1a depicts the situation in which a firm or a group of firms over-report their demand curves such that the reported aggregate demand curve is $\hat{P}(x)$ instead of the true curve $P(x)$. The license and subsidy parameters take the values of $\hat{l}$ and $\hat{s}$, respectively, which are above their first-best levels $l^{*}$ and $s^{*}$. Since the government is buying back licenses at price $\hat{s}$, the market equilibrium price of licenses is not $p^{\prime}$ (as if no license were sold back to the government) but $p=\hat{s}>p^{*}$. On aggregate, firms sell back $\hat{l}-\hat{x}$ licenses, so total pollution falls below its first-best level to $\hat{x}<l^{*}$. Figure $1 \mathrm{~b}$, on the other hand, depicts the under-reporting situation. Given the reported aggregate demand curve $\tilde{P}(x)$, the license and subsidy parameters take now the values of $\tilde{l}$ and $\tilde{s}$, respectively. The market equilibrium price is $p=\tilde{p}>p^{*}$ and total pollution is $x=\tilde{l}<l^{*}$.

From inspection of these two cases it should become evident that no matter what firms report to the regulator the market equilibrium price of licenses is given by $p=$ $\max \left\{P(x), D^{\prime}(x)\right\}$. Hence, the minimum possible equilibrium price for licenses is $p^{\min }=$ $P\left(x^{*}\right)=D^{\prime}\left(x^{*}\right)$, which is obtained when all firms report their true types. Based on this observation, Kwerel closes his proof by arguing that since each firm's compliance cost is an increasing function of $p$, no firm has incentives to move the aggregate demand curve from its actual value, whatever it is, when it believes that all the other firms are telling 
the truth. ${ }^{16}$

Kwerel's logic holds as long as all licenses are auctioned off and the (uniform-price) auction is competitive. In fact, if firms anticipate a competitive equilibrium at the auction it is a Nash equilibrium for them to report their true types in the first stage. The problem is that there are many other (inefficient) equilibria that are more profitable for firms. Consider, for example, a situation in which firms over-report their types to a large extent such that $\hat{l}$ and $\hat{s}$ are well above their first-best levels $l^{*}$ and $s^{*}$. When $\hat{s}$ is very large, $X_{i}(\hat{s})$ is approximately zero and the auction for the $\hat{l}$ licenses reduces to the Wilson's (1979) share auction in which each of the $n$ firms (where $n$ is large) has a reservation price of $\hat{s}$ for the licenses. Wilson shows that firms (non-cooperatively) bid less than their reservation values reaching an equilibrium price of $\hat{s} / 2$ (although we know from Milgrom (2004, pp. 262-64) that the range of price equilibria goes from 0 to $\hat{s}$ ). Firms would over-report their types to the maximum extent possible if they anticipate the Wilson equilibrium (or a similar low-price equilibrium) at the auction, because they could sell licenses back to the government at a higher price than they could acquire them in the auction. ${ }^{17}$

If, on the other hand, licenses are allocated for free, the revenues accruing to firms from selling licenses back to the government create over-reporting incentives. To see this, simply go back to Figure 1a and compare the total compliance costs from reporting the true aggregate demand curve $P(x)$, i.e., area $x^{0} l^{*} E$, with those from reporting $\hat{P}(x)$, i.e., area $x^{0} \hat{x} A$ minus area $\hat{l} \hat{x} A B$. Clearly, the regulation has turned out to be quite a profitable business for firms, and more so the higher the degree of over-reporting. More generally, it can be established

PROPOSITION 1: The unique (Nash-equilibrium) outcome in Kwerel's scheme under a free allocation of licenses is for firms to over-report their demand curves as to ensure the maximum possible number of licenses and subsidy level.

Despite its limitations, Kwerel's scheme has an element that I also use in constructing the auction mechanism that I present next. Under this new scheme firms are also communicated in advance that the information they report to the regulator will be used in a form similar to expression (2); although with some fundamental differences.

\footnotetext{
${ }^{16}$ Kwerel also mentions the existence of multiple "offsetting-lies" Nash equilibria in which two or more firms send false reports that, on aggregate, add to the true demand curve $P(x)$. Without knowing the actual $P(x)$, however, it is hard to see how firms could coordinate in one of these "offsetting-lies" Nash equilibria.

${ }^{17}$ Some readers may argue that removing the subsidy and having it replaced by a price floor (of equal magnitude) may solve matters. Not necessarily. If firms anticipate the reserve price as the auctionclearing price, firms would have incentives to under-report their types at the reporting stage in an effort to decrease the reserve price to the monopsony level. Note, however, that if firms anticipate an auctionclearing price equal or above the first-best level, $p^{*}$, it is in the firms' best interest to report their true types.
} 


\section{The Auction Mechanism}

It helps to start with the single-firm case. I will then extend the mechanism to the general case of multiple (non-cooperative) firms.

\section{A. Single Firm}

Consider a single firm with demand curve $P(x) \equiv-C^{\prime}(x)$. The auction scheme operates as follows. First, the firm is informed in advance about the auction rules (including the way the auction clears and the paybacks are computed). Then, the firm is asked to bid a non-increasing inverse demand schedule $\hat{P}(x)$ (or equivalently, a non-increasing demand schedule $\hat{X}(p)$ ). With this information, the auctioneer/regulator clears the auction (i.e., determines $p$ and $l$ ) according to

$$
p=\hat{P}(l)=D^{\prime}(l)
$$

The firm receives $l$ licenses and pay $p$ for each license. Soon after the firm gets a fraction $\alpha(l)$ of the auction revenues back (i.e., payback is $\alpha(l) p l$ ).

It is readily seen in Figures 1a and $1 \mathrm{~b}$ that it is not socially optimal for the regulator to set the fraction $\alpha(l)$ equal to either 1 or 0 . If the regulator keeps no revenue for himself (i.e., $\alpha(l)=1$ ), the firm has incentives to over-report by as much as to postpone any abatement effort. Conversely, if the regulator keeps all the auction revenues for himself (i.e., $\alpha(l)=0$ ), the firm has incentives to under-report to some optimal extent. By submitting $\tilde{P}(x)$ instead of $P(x)$ in Figure 1b, the firm is able to reduce its compliance cost from area $x^{0} 0 p^{*} E$ to area $x^{0} 0 \tilde{s} F B E$. The firm's optimal under-reporting in this case balances at the margin the gains from getting a lower price for licenses with the losses from higher abatement.

To find the function $\alpha(l)$ that just induces the firm to submit its true demand curve and hence allows the regulator to implement the first-best, we proceed by backward induction. Given some function $\alpha(l)$, the firm's problem is to find the demand schedule $\hat{P}(x)$ that solves

$$
\min C(l)+p l-\alpha(l) p l
$$

subject to (3).

Using the auction clearing equation (3) we can replace $p$ by $D^{\prime}(l)$ in (4), and since there is a one-to-one correspondence between a demand schedule $\hat{P}(x)$ and the number of licenses $l$, at least in the range of prices the firm expects the auction to clear, the firm's first order condition is given by

$$
C^{\prime}(l)+D^{\prime}(l)+D^{\prime \prime}(l) l-\alpha^{\prime}(l) D^{\prime}(l) l-\alpha(l)\left(D^{\prime \prime}(l) l+D^{\prime}(l)\right)=0
$$


Anticipating (5), the regulator's problem is to find the function $\alpha(l)$ that induces the firm to deliver the first-best allocation, i.e., $C^{\prime}\left(l^{*}\right)+D^{\prime}\left(l^{*}\right)=0\left(\right.$ or $\left.P\left(l^{*}\right)=D^{\prime}\left(l^{*}\right)\right)$. Such function solves the differential equation

$$
\alpha^{\prime}(l)+\alpha(l)\left(\frac{D^{\prime \prime}(l) l+D^{\prime}(l)}{D^{\prime}(l) l}\right)=\frac{D^{\prime \prime}(l)}{D^{\prime}(l)}
$$

The function $\alpha(l)$ that results from solving (6) is the function the regulator informs the firm along with the other auction rules. But if $\alpha(l)$ is such that the firm is delivering the first-best $l^{*}$ it must be the case that the firm is solving the regulator's problem up front. In other words, the last two terms of (4) must add to $D(l)$, which leads to

PROPOSITION 2: The payback function is given by ${ }^{18}$

$$
\alpha(l)=1-\frac{D(l)}{D^{\prime}(l) l}
$$

Since $D^{\prime}(l)$ is a non-decreasing function of $l, 0 \leq \alpha(l) \leq 1$ and the final price paid by the firm for each license, $(1-\alpha) p$, is at most equal to marginal damage $D^{\prime}(l)$. Plugging back the function $\alpha(l)$ of Proposition 2 into the firm's objective function (4) it is immediately seen that the new auction scheme has indeed converted the firm's problem into the regulator's by making the firm bear the full cost of the pollution damages.

The idea of requiring the firm to pay $D(l)$ is certainly not new. DHM and Kim and Chang (1993) for the case of a single firm reduce precisely to the regulator informing the firm that it faces a tax function $T(x)=D(x)$, where $x$ is the firm's observed pollution level (note also that because there is only one firm the regulator in DHM does not need the firm to report any cost/demand information to him). The auction mechanism implements the same result but in a different way. Here the regulator asks the firm to submit a demand schedule that it is then used to compute the optimal number of licenses and the price to be charged for each license. In that sense the auction scheme fully decouples the regulatory design from the enforcement/monitoring activity like in any other quantitybased regulation - whether it is based on standards or transferable licenses - which today is the more prevalent type of regulation for protecting the commons. Other differences will become evident as we consider more than one firm.

But before moving to the multiple-firm case it is worth mentioning that if our single firm knows the function $D(x)$, it does not need to truthfully bid its entire demand schedule but only the portion relevant to the auction clearing. It could for instance submit the perfectly inelastic demand schedule $\hat{X}(p)=l^{*}$. More importantly, although

\footnotetext{
${ }^{18}$ Strictly speaking the solution of $(6)$ is $\alpha(l)=1-D(l) / D^{\prime}(l) l+K / D^{\prime}(l) l$, where $K$ is an integration constant that represents - unless it is set to zero- a lump-sum transfer from(to) the firm.
} 
I have developed the auction mechanism as if the firm knew the damage function $D(x)$, it should be clear by now that the firm does not actually need to know $D(x)$, and hence $\alpha(l)$, for the auction mechanism to work in providing incentives for truthful revelation. We only require the firm to believe that it is facing a regulator committed to implement the first-best for whatever function $D(x)$ he has in mind. And if the firm does indeed know little about $D(x)$, it will truthfully bid its (almost) entire demand schedule to make sure that for any possible function $D(x)$ chosen by the regulator it will get the first-best level of licenses.

\section{B. Multiple Firms}

Consider now $n \geq 2$ firms. The auction mechanism extends as follows. Firm $i$ $(=1,2, \ldots, n)$ is asked to bid a non-increasing inverse demand schedule $\hat{P}_{i}\left(x_{i}\right)$ (or, equivalently, a non-increasing demand schedule $\left.\hat{X}_{i}(p)\right)$. Based on this information, the regulator computes the residual supply function (i.e., residual marginal damage function) for each firm $i$ using the other firms' reported demand schedules, that is

$$
S_{i}(p)=S(p)-\hat{X}_{-i}(p)
$$

where $\hat{X}_{-i}(p)=\sum_{j \neq i} \hat{X}_{j}(p)$ and $D^{\prime}(x)=S^{-1}(p)$. As shown in Figure 2, the residual marginal damage function $D_{i}^{\prime}\left(x_{i}\right)=S_{i}^{-1}(p)$ is only defined at and above the point at which $D^{\prime}(x)=\hat{P}_{-i}\left(x_{-i}\right)=\hat{p}_{-i}$. The regulator clears the auction by determining a price $p_{i}$ and number licenses $l_{i}$ for each bidder $i$ according to

$$
p_{i}=\hat{P}_{i}\left(l_{i}\right)=D_{i}^{\prime}\left(l_{i}\right)
$$

or, equivalently, $l_{i}=S_{i}\left(p_{i}\right)=\hat{X}_{i}\left(p_{i}\right)$.

Since the efficient equilibrium price, given $\hat{X}_{-i}(p)$ and $\hat{X}_{i}(p)$, solves $\hat{X}_{i}(\hat{p})=S(\hat{p})-$ $\hat{X}_{-i}(\hat{p})$, by making firm $i$ face the marginal damage curve $(7)$, we are basically informing the firm that for whatever demand report it chooses to submit to the regulator/auctioneer, its report, together with those of the other firms, will be used efficiently.

As in the single-firm case, firm $i$ purchases $l_{i}$ licenses at a price $p_{i}$ each, and soon after gets a payback of $\alpha_{i}\left(l_{i}\right) p_{i} l_{i}$, where $\alpha_{i}\left(l_{i}\right)$ is the payback fraction specific to firm $i$. If $\alpha_{i}\left(l_{i}\right)$ is set according to Proposition 2, i.e.,

$$
\alpha_{i}\left(l_{i}\right)=1-\frac{D_{i}\left(l_{i}\right)}{D_{i}^{\prime}\left(l_{i}\right) l_{i}}
$$

where $D_{i}\left(l_{i}\right)=\int_{0}^{l_{i}} D_{i}^{\prime}(z) d z$ is $i$ 's residual damage function, then 
PROPOSITION 3: It is optimal for each firm $i$ to bid its true demand curve $P_{i}\left(x_{i}\right)$ regardless of what other firms bid.

Truth-telling is a dominant strategy for firms, so there is no need for them to form beliefs about other firms' types and/or actions. This efficient and strategy-proof result is not surprising once we realize that the auction mechanism follows a VCG payoff rule: it makes each firm $i$ pay for its (residual) damage $D_{i}\left(l_{i}\right)$ to all other agents. This residual damage includes both the pecuniary externality imposed upon other regulated firms and the pollution externality imposed upon society. ${ }^{19}$

One immediate implication of Proposition 3 is that the auction scheme implements the first-best with each firm facing the same price at the margin (i.e., $p_{i}=p^{*}$ for all $i$ ) and getting exactly the first-best allocation of licenses (i.e., $l_{i}=x_{i}^{*}$ ), which eliminates (efficiency) reasons for trading licenses after the auction. These efficiency properties can be readily seen in Figure 2: if $\hat{P}_{i}\left(x_{i}\right)=P_{i}\left(x_{i}\right)$ and $\hat{P}_{-i}\left(x_{-i}\right)=P_{-i}\left(x_{-i}\right)$, then $l_{i}=x_{i}^{*}$, $l=x^{*}$ and $\hat{p}=p^{*}$. Although it appears the auctioneer (i.e., regulator) goes bidder after bidder determining individual prices $p_{i}$, these prices are all the same regardless of how truthful firms are (in terms of Figure 2: $p_{1}=\ldots=p_{n}=\hat{p}$ ). But unless firms have identical demand curves, final prices $\left(1-\alpha_{i}\right) p$ will differ across firms. Note also that as we increase the number of firms, firm $i$ has virtually no effect on the equilibrium price, so $D_{i}^{\prime}\left(x_{i}^{*}\right) \approx D_{i}^{\prime}(0)$ and $\alpha_{i}\left(l_{i}\right) \approx 0$; hence, the auction schem has converged to the Pigouvian principle for taxing externalities.

\section{Properties of the Mechanism}

Besides being ex-post efficient and strategy-proof, the auction mechanism have additional properties that may prove relevant for purposes of practical implementation. We leave the analysis of collusion for the next section. ${ }^{20}$

\section{A. Relationship to the VCG-DHM Mechanism}

Notwithstanding the auction mechanism follows a VCG payoff rule, it is structurally different than the VCG tax mechanism of DHM. Without any loss of generality, let parametrize firm $i$ 's identity as $C_{i}\left(x_{i}\right) \equiv C\left(x_{i}, \theta_{i}\right)$, where $\theta_{i}$ is firm $i$ 's true type. In DHM firm $i$ faces a tax schedule equal to

$$
T_{i}\left(x_{i}, \hat{\theta}_{i}, \hat{\boldsymbol{\theta}}_{-i}\right)=D\left(x_{i}+\sum_{j \neq i} x_{j}^{*}\left(\hat{\theta}_{i}, \hat{\boldsymbol{\theta}}_{-i}\right)\right)+\sum_{j \neq i} C\left(x_{j}^{*}\left(\hat{\theta}_{i}, \hat{\boldsymbol{\theta}}_{-i}\right), \hat{\theta}_{j}\right)-A_{i}\left(\hat{\boldsymbol{\theta}}_{-i}\right)
$$

\footnotetext{
${ }^{19}$ The presence of firm $i$ not only adds to the total amount of pollution (pollution externality) but also makes it more expensive to other firms to comply with the regulation by driving up the equilibrium price of licenses (pecuniary externality). Note then that when $D^{\prime}(x)$ is perfectly inelastic (elastic) there is no pollution (pecuniary) externality.

${ }^{20}$ Other properties regarding budget balancing, off-equilibrium behavior and the speed at which paybacks decline with the number of firms can be found in Montero (2007).
} 
where $\hat{\theta}_{i}$ is firm $i$ 's report to the regulator, $\hat{\boldsymbol{\theta}}_{-i}$ is the vector of firms $j \neq i$ 's reports, $x_{j}^{*}\left(\hat{\theta}_{i}, \hat{\boldsymbol{\theta}}_{-i}\right)$ is firm $j$ 's first-best pollution level as dictated by the reports of all firms, and $A_{i}$ is a constant term independent of firm $i$ 's report. Although the exact value of $A_{i}$ does not alter firm $i$ 's report at the margin (we could in principle set it equal to zero as in the Groves mechanism), we know that for DHM to be a VCG mechanism the constant term $A_{i}$ is equal to the efficient social cost had firm $i$ not existed, that is

$$
A_{i}\left(\hat{\boldsymbol{\theta}}_{-i}\right)=D\left(x_{-i}^{* *}\right)+\sum_{j \neq i} C\left(x_{j}^{* *}\left(\hat{\boldsymbol{\theta}}_{-i}\right), \hat{\theta}_{j}\right)
$$

where $x_{-i}^{* *} \equiv \sum_{j \neq i} x_{j}^{* *}\left(\hat{\boldsymbol{\theta}}_{-i}\right)$ and $x_{j}^{* *}\left(\hat{\boldsymbol{\theta}}_{-i}\right)$ is firm $j$ 's first-best pollution level in the absence of firm $i$.

Firm $i$ 's total payment under the auction mechanism and under the DHM tax mechanism are exactly the same in equilibrium (but not off-equilibrium). This can be easily shown with the aid of Figure 2. Firm $i$ 's total payment under the auction mechanism is the shaded area on the left while the payment under the DHM mechanism is the shaded area on the right (recall that $\left.l_{i}=\hat{x}-\hat{x}_{-i}\right) \cdot{ }^{21}$

Despite this payoff equivalence, it is important to keep in mind that payments and allocations are computed in different ways. In DHM, the regulator uses the information provided by firms to compute the "overall" first-best equilibrium and make each firm to bear the full social cost. In fact, making $A_{i}\left(\hat{\boldsymbol{\theta}}_{-i}\right)=0$ in (8), firm $i$ 's total compliance cost becomes, in equilibrium, $C_{i}\left(x_{i}\right)+T_{i}\left(x_{i}\right)=C(x)+D(x)$. The constant term $A_{i}$ is then used as a lump-sum instrument to reduce payment $T_{i}\left(x_{i}\right)$ to its "residual" level. In contrast, in the auction mechanism, the regulator uses the information provided by firms to compute a "residual" equilibrium for each firm, simultaneously determining the firm's equilibrium number of licenses and payments. These structural differences explain why in some circumstances (e.g., perfectly inelastic supply) the auction mechanism continues to perform equally well, i.e., delivering the first-best, while DHM does not.

\section{B. Perfectly Elastic/Inelastic Functions}

\footnotetext{
${ }^{21}$ These payments can also be readily compared to those under Kim and Chang's (1993) mechanism (we abstract from the output market). The tax schedule of Kim and Chang is given by

$$
T\left(x_{i}\right)=D\left(x_{i}+x_{-i}^{*}\right)-D\left(x_{-i}^{* *}\right)
$$

where $x_{-i}^{*}$ and $x_{-i}^{* *}$ are defined as before (note that unlike in DHM or in the auction mechanism, firms must form expectations about $x_{-i}^{*}$ before solving for $x_{i}$ ). Thus, in terms of Figure 2, firm $i$ 's equilibrium payment is the area under $D^{\prime}(x)$ from $\hat{x}_{-i}$ to $\hat{x}$. The reason Kim and Chang's payment is smaller than DHM's and the auction's is because it does not pay explicit attention to the additional cost that the presence of firm $i$ imposes upon other regulated firms; only indirectly through the equilibrium quantity $x_{-i}^{*}$.
} 
It is well known that if $D^{\prime}(x)$ is constant a first-best policy is to charge a Pigouvian tax equal to $D^{\prime}$. The auction mechanism is equivalent to this tax policy in that paybacks are exactly equal to zero but it still has the (practical) advantage that the socially efficient amount of pollution is set ex-ante, i.e., before pollution occurs.

More interestingly, if the supply curve is totally inelastic, say, at $x=\bar{x}$, whether because there is a genuine threshold at $\bar{x}$ or because the regulator has no control over $x$, the auction mechanism still retains its truth-telling properties (firm $i$ continues facing the residual supply function $S_{i}(p)=\bar{x}-\hat{X}_{-i}(p)$, so nothing fundamental has changed in the analysis of II.B). ${ }^{22}$ This latter has two important implications. On the one hand, it makes the auction mechanism readily comparable to the (fixed-supply) private-value auctions of Vickrey (1961) and Ausubel (2004). In fact, the three auctions yield the same outcome in terms of revenues and allocations; although they are implemented in different ways.

On the other hand, it introduces an important distinction between the auction mechanism and the DHM mechanism. Since total pollution is fixed at $\bar{x}$ with or without firm $i$, tax schedule (8) reduces to

$$
T_{i}\left(x_{i}, \hat{\theta}_{i}, \hat{\boldsymbol{\theta}}_{-i}\right)=\sum_{j \neq i} C\left(x_{j}^{*}\left(\hat{\theta}_{i}, \hat{\boldsymbol{\theta}}_{-i}\right), \hat{\theta}_{j}\right)-\sum_{j \neq i} C\left(x_{j}^{* *}\left(\hat{\boldsymbol{\theta}}_{-i}\right), \hat{\theta}_{j}\right)
$$

Firm $i$ is only paying for the additional cost that is inflicting upon other firms but is no longer pivotal in the sense that its report does not affect the aggregate supply. In such a case, firm $i$ would rather submit a null report reducing its tax schedule $T_{i}$ to zero. ${ }^{23}$ The auction mechanism avoids that problem due to its quantity-based structure: if a firm submits an empty demand schedule it gets no licenses. What induces a firm to tell the truth in DHM is its effect on total pollution, which is channeled through the term $D\left(x_{i}+\sum_{j \neq i} x_{j}^{*}\left(\hat{\theta}_{i}, \hat{\boldsymbol{\theta}}_{-i}\right)\right)$ in (8). ${ }^{24}$ A perfectly inelastic supply curve eliminates that channel, giving raise to a multiplicity of Nash Bayesian equilibria. ${ }^{25}$

\footnotetext{
${ }^{22}$ There is, however, one exception: the "single" firm will no longer submit its true demand curve but $\hat{P}(x)=0$. But since $x$ is fixed and there is only one firm, this has no allocative implications.

${ }^{23}$ Regardless of whether firms tell the truth or not, we would still need to define what happens if $\sum x_{i}>\bar{x}$. They will have to pay a high penalty for pollution above $\bar{x}$, however it is defined (e.g., $f \gamma x_{i}$, where $\gamma=\bar{x} / \sum x_{i}$ and $f$ is the penalty fee).

${ }^{24}$ When firm $i$ reports a null type (or something lower than its true type), the term $D\left(x_{i}+\right.$ $\left.\sum_{j \neq i} x_{j}^{*}\left(\hat{\theta}_{i}, \hat{\boldsymbol{\theta}}_{-i}\right)\right)$ - provided that the aggregate supply is not fixed- $\operatorname{shifts}$ up because $x_{j}^{*}\left(\hat{\theta}_{i}, \hat{\boldsymbol{\theta}}_{-i}\right)$ is a decreasing function of $\hat{\theta}_{i}$. And the increase in $D\left(x_{i}+\sum_{j \neq i} x_{j}^{*}\left(\hat{\theta}_{i}, \hat{\boldsymbol{\theta}}_{-i}\right)\right)$ is only partially offset by the fall of $\sum_{j \neq i} C\left(x_{j}^{*}\left(\hat{\theta}_{i}, \hat{\boldsymbol{\theta}}_{-i}\right), \hat{\theta}_{j}\right)$ up to the deadweight loss.

${ }^{25}$ Suppose, for example, that each of the (asymmetric) $n$ firms submit a null report and then emit $\bar{x} / n$. This (socially inefficient) equilibrium strategy reduces tax payments to zero and clearly no firm wants to deviate from it (provided that the penalty fee for pollution above $\bar{x}$ is sufficiently large). Note that, for the same reasons, Kim and Chang (1993) also allocate pollution inefficiently when $S(p)$ is perfectly inelastic.
} 
DHM may face a similar problem with demand curves that exhibit flat portions. If a firm believes that the equilibrium is likely to lie on a perfectly elastic portion of the aggregate demand curve irrespective of its report, it would be better off by submitting a null report. This is because the firm is, as before, no longer pivotal as to affect the aggregate supply. ${ }^{26}$

\section{Shadow Cost of Public Funds}

Rebates may be costly to the regulator in that they could be used to reduce distortionary taxation somewhere else in the economy (A. Lans Bovenberg and Lawrence H. Goulder, 1996). For simplicity consider a single firm. The regulator's problem then becomes

$$
\min D(l)+C(l)+\lambda \alpha(l) D^{\prime}(l) l
$$

where $\lambda$ is the shadow cost of public funds. The full-information social optimum is implemented by setting $\alpha(l)=0$ and the Pigouvian tax $\tau=D^{\prime}\left(l^{*}\right)=-C^{\prime}\left(l^{*}\right)$.

Under incomplete information, however, the regulator faces a trade-off between allocative efficiency and information rent extraction. Since the firm's problem remains unchanged (i.e., min $C(l)+(1-\alpha(l)) p l$, where $\left.p=D^{\prime}(l)\right)$, the payback function that best solves the regulator's trade-off is given by (its derivation follows that of Proposition 2)

$$
\alpha(l)=\frac{1}{1+\lambda}\left(1-\frac{D(l)}{D^{\prime}(l) l}\right)
$$

which, in turn, leads to the "shadow-cost" equilibrium condition

$$
D^{\prime}\left(l^{s c}\right)+C^{\prime}\left(l^{s c}\right)+\frac{\lambda D^{\prime \prime}\left(l^{s c}\right) l^{s c}}{1+\lambda}=0
$$

Unless $D^{\prime}(\cdot)$ is flat (in the relevant range), $l^{s c}<l^{*}$. That pollution levels are lower under asymmetric information is consistent with second-degree price discrimination principles. Note that equilibrium paybacks (i.e., information rents) are equal to $\left(D^{\prime}(l) l-D(l)\right) /(1+$ $\lambda$ ), which are increasing in $l$, or equivalently, in $P(\cdot)$. It should be nevertheless clear that

\footnotetext{
${ }^{26}$ An example may help. Consider the marginal damage function $D^{\prime}(x)=x$ and two firms, 1 and 2 . The true demand curve of firm 1 is given by: $P_{1}\left(x_{1}\right)=5$ for $0 \leq x_{1}<3, P_{1}\left(x_{1}\right)=2$ for $3 \leq x_{1}<4$ and $P_{1}\left(x_{1}\right)=0$ for $4 \leq x_{1}$; and the demand curve of firm 2 is given by: $P_{2}\left(x_{2}\right)=4$ for $0 \leq x_{2}<6$ and $P_{2}\left(x_{2}\right)=0$ for $6 \leq x_{2}$. The first-best is $x_{1}^{*}=3$ and $x_{2}^{*}=1$. In the absence of firm 1 , the efficient amount of pollution is also 4 units, i.e., $x_{2}^{* *}=4$. Firm 1's DHM payment would be, assuming truth-telling, the additional cost to firm 2, that is $12=20-8$. But if firm 1 anticipates that its report is unlikely to affect total pollution, it would rather submit a null report, pay no taxes and emit its no-regulation level $x_{1}^{0}=4$. Under the auction mechanism, firm 1 faces a residual marginal damage curve given by: $D_{i}^{\prime}\left(x_{1}\right)=4$ for $0 \leq x_{1}<4$ and $D_{i}^{\prime}\left(x_{1}\right)=D^{\prime}\left(x_{1}\right)=x_{1}$ for $4 \leq x_{1}$. It is optimal for firm 1 to bid its true demand schedule, receive 3 licenses and pay a total of $12=4 \cdot 3$ for the licenses.
} 
the auction mechanism is not second-best optimum because it does not pay attention to any prior information the regulator may have about the firm's type. A truly secondbest scheme can at worst replicate the (incentive-compatible) auction outcome but it will generally improve upon it. ${ }^{27}$

\section{Dynamics and Investment}

Consider two dates, $t=1,2$, and $n \geq 1$ firms. For notational simplicity assume no discounting. Firm $i$ 's abatement costs at date 1 are $C_{i}\left(x_{i}\right)$ but at cost $I_{i}$ incurred at date 1 it can reduce its abatement costs at date 2 to $C_{i}\left(x_{i}, I_{i}\right)$, where $I_{i}$ is the (irreversible) amount of R\&D investment in more efficient technologies and $\partial C_{i}\left(x_{i}, I_{i}\right) / \partial I_{i}<0$ for all $x_{i}$. Demand schedules for periods 1 and 2 are, respectively, $P_{i}\left(x_{i}\right)=-C_{i}^{\prime}\left(x_{i}\right)$ and $P_{i}\left(x_{i}, I_{i}\right)=-\partial C_{i}\left(x_{i}, I_{i}\right) / \partial x_{i}$. The damage function in each period is $D(x)$, where $x=$ $\sum x_{i}$. First-period social optimum is well known: $D^{\prime}(x)+C_{i}^{\prime}\left(x_{i}\right)=0$ for all $i=1, \ldots, n$. The social optimum for second-period pollution and first-period R\&D is given by the first-order conditions

$$
\begin{gathered}
\frac{\partial C_{i}\left(x_{i}, I_{i}\right)}{\partial x_{i}}+D^{\prime}(x)=0 \\
\frac{\partial C_{i}\left(x_{i}, I_{i}\right)}{\partial I_{i}}+1=0
\end{gathered}
$$

for all $i=1, \ldots, n$.

Most regulations, whether command-and-control or market-based, will fail to yield (10)-(11) because of incomplete information (regarding abatement costs and investments), time inconsistency and/or strategic interactions (e.g., Gary Biglaiser et. al, 1995; Laffont and Jean Tirole, 1996). The auction mechanism is immune to such problems. The regulator must run two separate auctions: for period-1 licenses and for period-2 licenses. Since firms do not perfectly know each other, period-2 licenses must also be auctioned off at date 1 , i.e., before investments take place. ${ }^{28}$ In allocating period-2 licenses each firm $i$ is asked to bid a demand schedule $\hat{P}_{i}\left(x_{i}, I_{i}\right)$, which must be a function of the different investment levels firm $i$ may pursue. These bids are then used by the regulator to clear the auction (i.e., determine price and license allocations), which necessarily requires him to identify firms' efficient investments. Note, however, that the regulator does not need to later verify these investments; it is in the firms' best interest to carry them through.

In deciding whether to submit its true demand schedule $P_{i}\left(x_{i}, I_{i}\right)$, firm $i$ solves the

\footnotetext{
${ }^{27}$ The auction mechanism still has the advantage of simplicity vis-a-vis a menu of a large number of contracts. Numerical exercises can shed light on welfare differences between the two schemes.

${ }^{28}$ If firms have complete information (but not the regulator) period-2 licenses can be auctioned off at date 2.
} 
problem

$$
\min _{l_{i}, I_{i}} C_{i}\left(l_{i}\left(I_{i}\right), I_{i}\right)+D_{i}\left(l_{i}\left(I_{i}\right) ; I_{-i}\right)+I_{i}
$$

where $l_{i}\left(I_{i}\right)$ is the number of licenses going to firm $i$, which is contingent upon its own investment, and $D_{i}\left(l_{i}\left(I_{i}\right) ; I_{-i}\right)$ is the associated total payment, i.e., firm $i$ 's residual damage. ${ }^{29}$ The first-order condition for $l_{i}$ is $\partial C_{i}\left(l_{i}, I_{i}\right) / \partial l_{i}+\partial D_{i}\left(l_{i}\right) / \partial l_{i}=0$ and the first-order condition for $I_{i}$ is

$$
\frac{\partial C_{i}\left(l_{i}\left(I_{i}\right), I_{i}\right)}{\partial I_{i}}+1+\left(\frac{\partial C_{i}\left(l_{i}\left(I_{i}\right), I_{i}\right)}{\partial l_{i}}+\frac{\partial D_{i}\left(l_{i}\left(I_{i}\right)\right)}{\partial l_{i}}\right) \frac{d l_{i}\left(I_{i}\right)}{d I_{i}}=0
$$

Since $\partial D_{i}\left(l_{i}\right) / \partial l_{i}=D^{\prime}(l)$ for all $i$, the auction mechanism clearly induces firms to bid truthfully and, hence, to invest and abate optimally from a social standpoint..$^{30,31}$

\section{E. Asymmetric Information on the Supply Side}

Suppose that part or all of the information needed by the regulator to construct $D^{\prime}(x)=S^{-1}(p)$ is in private hands. Understanding that pollution reduction is a public good, the auction mechanism incorporates these new privately informed agents under the same VCG principle: each agent pays for the externality (i.e., residual damage) it exerts upon the other agents. Unlike polluting firms, these "supply-side" agents can be viewed as buying "pollution-reduction" licenses. Figure 3 depicts the non-decreasing marginal damage schedule (or non-increasing marginal benefit schedule from reducing total pollution below $x^{0}$ ) reported by agent $k$ as a function of total pollution $x$ to the regulator, $\hat{D}_{k}^{\prime}(x)$. Note that $\hat{D}^{\prime}(x)=\hat{D}_{k}^{\prime}(x)+\hat{D}_{-k}^{\prime}(x)$. The agent is informed in advance that his reported schedule together with its residual demand schedule $\hat{R}_{k}(x)=\hat{P}(x)-$ $\hat{D}_{-k}^{\prime}(x)$ will be used to determine the number of reduction licenses allocated to him, $r_{k}=\hat{x}_{-k}-\hat{x}$, and the Lindahl price $\hat{p}_{k}$ to pay for each of them. To induce the agent to report its true schedule $D_{k}^{\prime}(x)$, the payback function is, as before, $\alpha_{k}\left(r_{k}\right)=1-\hat{C}_{k}\left(\hat{x}_{-k}-\right.$

\footnotetext{
${ }^{29}$ I have deliberately included $I_{-i}$ in $D_{i}(\cdot)$ to emphasize that investments by firms other than $i$ enter optimally into $D_{i}(\cdot)$ as dictated by first-order conditions (10) and (11). For example, to find the equivalent of $\hat{p}_{-i}$ of Figure 2, we use the vector of $n-1$ reports $\hat{\mathbf{P}}_{-i}$ to solve (10) and (11). The rest of the curve $D_{i}^{\prime}(\cdot)$ is constructed by computing at any $p>\hat{p}_{-i}$ the abatement/investment response of each firm $j \neq i$.

${ }^{30}$ Note that if period- 2 damages are uncertain at date 1 - so the regulator operates under an expected damage function - investments will not be necessarily optimal ex-post, i.e., at date 2. Given those investments, the regulator can nevertheless implement optimal levels of abatement at date 2 by selling (or buying back) additional licenses with the same auction mechanism.

${ }^{31}$ Note that the results of this section extend to a multiperiod model in which firm $i$ expects its cost function at period $t, C_{i}^{t}\left(x_{i}^{t}, K_{t}^{t}\right)$, be a function of cumulative R\&D according to $K_{i}^{t}=\rho K_{i}^{t-1}+I_{i}^{t}$ (with $\rho<1$ and $K_{i}^{0}=0$ ). However, if cumulative R\&D depends on other firms' previous investments, additional instruments are required to restore (ex-ante) efficiency.
} 
$\left.r_{k}\right) / r_{k} \hat{R}_{k}\left(\hat{x}_{-k}-r_{k}\right)$, where $\hat{C}_{k}(\cdot)=\int_{r_{k}}^{0} \hat{R}_{k}\left(\hat{x}_{-k}-z\right) d z$. Thus, agent $k$ 's total payment in Figure 3 is area $A .{ }^{32}$

\section{Collusion}

The workings of bidding rings or auction cartels have received a fair amount of theoretical and empirical attention in the auction literature (e.g., R. Preston McAfee and John McMillan, 1992; Klemperer, 2004). In this section I discuss how the auction scheme proposed in this paper performs under collusive behavior, if sustainable, and whether it requires of any adjustment in order to preserve its first-best properties.

The way to implement a collusive agreement in our multi-unit auction is not very different from the description of McAfee and McMillan (1992) for a single-unit auction except for some elements that I will explain below. Cartel firms need to both coordinate on their bidding schedules and agree on the procedure for sharing the cartel profits. But because cartel members do not know each other's demand curves, in implementing the collusive agreement the cartel organization must itself overcome an adverse-selection problem: it must induce its members to truthfully reveal their private information. In other words, the cartel itself faces an internal mechanism design problem. I will first present the optimal (i.e., maximal profits) collusive agreement and then an internal mechanism the cartel can use to implement such outcome.

\section{A. Optimal Collusive Agreement}

Imagine for a moment that there is a relatively large number of independent production plants. In the non-cooperative equilibrium each plant $i$ operates at its first-best level $x_{i}^{*}$ and receives virtually no payback. Imagine now that all those plants belong to a single holding company subject to the same auction scheme. The holding company is clearly better off because is not only operating at the same level $\left(x_{i}^{*}\right.$ at plant $i=1, . . n$ ) but also receiving a strictly positive payback $\left(1 / 2\right.$ of the auction revenues if $\left.D^{\prime}(x)=h x\right)$. A good collusive agreement would then be for plants to coordinate as if they were acting as a single entity. In fact, it can be established

PROPOSITION 4: The optimal collusive agreement for a cartel of $m \leq n$ firms is to submit only one serious bid with the true aggregate demand curve of the cartel, say $P_{c}\left(x_{c}\right)$. One cartel member submits the serious bid while all the other members submit empty demand schedules. The optimal collusive agreement delivers the first-best allocation.

\footnotetext{
${ }^{32}$ Not surprisingly, if DHM were to be extended to include these new privately-informed agents, their (equilibrium) payments will be the same, although computed differently (area $D$ in Figure 3). Note also that as we increase the number of these "supply-side" agents, their payments and reduction contributions go to zero and with that, their interest to participate in the auction.
} 
With transferable licenses firms can behave as a single entity at the auction and then proceed with license transfers as required by the collusive aggrement. There are three interrelated reasons of why firms want to do that. First, paybacks for any given level of licenses are largest when the cartel faces the total supply function instead of a series of residual supply functions. Second, clean-up costs for any given level of licenses are lowest when they can be split cost-effectively across all firms in the cartel. Third, the single-firm analysis has already shown that the level of licenses that minimizes overall costs (clean-up costs and payments) is the first-best level.

These same three reasons also help explaining why cartel profits are increasing with the number of cartel members. Unlike in the single-unit auctions of McAfee and McMillan (1992), where the addition of a "low-valuation" member only contributes to dissipate cartel rents, in our multi-unit auction the most profitable cartel is an all-inclusive cartel (i.e., $m=n$ ). Existing members may eventually restrict additional participation insofar as it helps to prevent detection by antitrust authorities.

There are two additional observations. First, from looking at expression (8) it is not difficult to see that a collusive agreement, if implementable, under the DHM mechanism would depart from the first-best allocation. Since tax schedules are by definition not transferable, the only way for firms to cooperatively reduce their payments is by some over-reporting of their types. ${ }^{33}$ However, if the constant term in DHM, $A_{i}\left(\hat{\boldsymbol{\theta}}_{-i}\right)$, is set to zero, collusion is no longer an issue for firms but individual payments of the (now Groves) mechanism would suffer a substantial increase - the full social cost.

Second, there are in principle other and less profitable collusive agreements under the auction mechanism. For example, if firms restrained themselves from transfering licenses after the auction, they could still reduce their payments by cooperatively under-reporting their demands to some extent (as a way to decrease their residual supply curves). ${ }^{34} \mathrm{~A}$ sub-optimal agreement like this would certainly move us away from the first best. But there is no good reason for firms to ever coordinate on a sub-optimal agreement if they can enforce the optimal agreement, as I argue in the next section.

\section{B. Implementing the Collusive Agreement}

The arguments made thus far have assumed that the cartel submits only one serious

\footnotetext{
${ }^{33}$ The optimal (all-inclusive) collusive agreement under DHM is defined by the $n$-report vector $\hat{\boldsymbol{\theta}}$ that solves

$$
\min \left(\sum_{i=1}^{n} C\left(x_{i}\left(\hat{\boldsymbol{\theta}}, \theta_{i}\right), \theta_{i}\right)+D(x)\right) \cdot n-\sum_{i=1}^{n} A_{i}\left(\hat{\boldsymbol{\theta}}_{-i}\right)
$$

where $x=\sum x_{i}\left(\hat{\boldsymbol{\theta}}, \theta_{i}\right)$. From an envelope argument, we know that a marginal over-reporting of types only affects (i.e., increase) the $A_{i}$ 's.

${ }^{34}$ Note again that differences in payment structures explain why collusive firms (with no "transfer" of tax schedules/licenses) over-report in DHM and under-report in the auction mechanism.
} 
bid and this is the aggregate demand of cartel members. To do this, however, the cartel has to induce its members to truthfully reveal their individual demand curves. In addition, collusive profits have to be shared among the members in a way that the members would wish to participate in the cartel and not to deviate at the auction.

McAfee and McMillan (1992) explain that there are typically two forms of cartel organization: weak cartels, cartels whose members are unable to make transfer payments among themselves, and strong cartels, cartels whose members can both make transfer payments and exclude new entrants. While either type of organization may eventually arise in the single-unit auctions of McAfee and McMillan (1992), for the multi-unit auctions studied in this paper strong cartels appear more likely for the reason that licenses are easily transferable. ${ }^{35}$

Consider a potential strong cartel of $m \leq n$ members indexed as $j=1, \ldots, m$. In implementing the optimal collusive agreement of Proposition 4, the cartel organization must solve two intertwined problems. First, it must put in place an internal scheme that induces firms to truthfully reveal their individual demand curves to the cartel organization, which, as in McAfee and McMillan (1992), we will call the cartel mechanism. Second, the cartel must ensure obedience to the cartel mechanism, that is, it must be equipped with the ability to detect and credibly punish deviators.

Suppose for now that cartel has solved the second problem (I will come back to this shortly) and focus on the first problem. In so doing, consider the following cartel mechanism. Prior to the official auction, cartel members first agree on how to divide cartel profits by determining shares $\omega_{j}>0$, where $\sum_{j=1}^{m} \omega_{j}=1$. One plausible criteria can be historic use of the resource, that is $\omega_{j} \approx x_{j}^{0} / \sum_{k=1}^{m} x_{k}^{0}$ (in McAfee and McMillan (1992) $\left.\omega_{j}=1 / m\right)$. Cartel profits are defined as the difference between the payment associated to the optimal agreement and the sum of the non-cooperative payments that cartel members would have faced at the auction for the same demand schedules reported to the cartel mechanism. After $\omega_{j}$ 's are set, cartel members report their demand schedules $\tilde{P}_{j}\left(x_{j}\right)$ to the cartel mechanism. Let $\tilde{P}_{c}\left(x_{c}\right)$ denote the aggregate demand curve reported by cartel members. The cartel mechanism selects an arbitrary member to be the serious bidder, say bidder 1 , which bids $\hat{P}_{1}\left(x_{1}\right)=\tilde{P}_{c}\left(x_{1}\right)$. Remaining cartel members bid $\hat{X}_{j}(p)=0$ for

\footnotetext{
${ }^{35}$ In the absence of after-auction transfers, a weak cartel must conform itself with a sub-optimal collusive agreement in which each member (tacitly or not) agree on shading their bids to some extent. Since a firm's dominant strategy at the auction is to bid truthfully, a necessary condition for the sustainability of such an agreement is that cartel members can detect deviations at the auction. But unlike in the single-object auction of McAfee and McMillan (1992), where "weak-cartel" members coordinate on bidding the seller's reserve price, detecting deviations in the multi-unit auction mechanism requires cartel members to have information on demand curves. In the absence of transfers, it is impossible for the cartel to devise an internal (incentive-compatible) mechanism that can provide cartel members with such information prior to the auction. Perhaps, this information may become available over time as firms interact repeatedly.
} 
all $j=2, \ldots, m$.

The cartel mechanism also establishes the way licenses and payments are transferred across cartel members posterior to the auction. Let denote by $l_{c}$ the number of licenses received by the serious bidder at the auction and by $D_{c}\left(l_{c}\right)$ the corresponding payment, where $D_{c}\left(x_{c}\right)$ is the residual damage function faced by the cartel. The cartel mechanism establishes that each cartel member $j$ will receive an amount of licenses exactly equal to what he would have individually obtained at the auction for the demand curve that he reported to the mechanism. Member $j$ 's total payment for the $l_{j}$ licenses will be equal to what he would have individually paid at the auction, $D_{j}\left(l_{j}\right)$, minus a fraction $\omega_{j}$ of the cartel profits. Payment $D_{j}\left(l_{j}\right)$ is computed as in the auction mechanism, that is, using the aggregate demand curve reported by the remaining cartel members, $\tilde{P}_{-j}\left(x_{-j}\right)$. More precisely, $D_{j}\left(x_{j}\right) \equiv \int_{0}^{x_{j}} D_{j}^{\prime}(z) d z$, where $D_{j}^{\prime}\left(x_{j}\right) \equiv D_{c}^{\prime}\left(x_{c}\right)-\tilde{P}_{-j}\left(x_{-j}\right)$ for all $j .^{36}$

PROPOSITION 5: Assuming that the cartel members can agree on the $\omega_{j}$ 's, it is a dominant strategy Nash equilibrium for them to report truthfully to the cartel mechanism, i.e., $\tilde{P}_{j}\left(x_{j}\right)=P_{j}\left(x_{j}\right)$ for all $j=1, \ldots, m \leq n$.

Before moving onto the cartel's second implementation problem, that of obedience with the cartel mechanism, let me briefly touch on three issues. First, the cartel mechanism proposed above is not the only (incentive-compatible) mechanism available to the cartel. It has the advantage, however, that by sharing the format of the auction mechanism it makes it easier for members to understand its workings.

Second, I have little to add on how firms will come to an agreement on the $\omega_{j}$ 's other than pointing out that I see no reason for negotiations to fall apart because it is all about splitting spoils of unknown but positive magnitude. In other words, the bargaining process for setting the $\omega_{j}$ 's does not involved the type of information asymmetries that are usually associated to negotiation failure (e.g., Wiggins and Libecap, 1985).

Third, the cartel mechanism (whether the one proposed here or any other) must be executed in its entirety prior to the official auction, except for the actual transfer of licenses (and payments) across cartel members. Unlike in a single-object auction where the cartel mechanism (e.g., "knockout" auction) that decides which of the cartel members will keep the object can be conducted either before or after the official auction (McAfee and McMillan, 1992), in our multi-unit environment this is simply not possible for both information and incentive reasons. On the one hand, the serious bidder must be informed of $\tilde{P}_{c}\left(x_{c}\right)$ before coming to the official auction. On the other hand, the use of any ex-post

\footnotetext{
${ }^{36}$ In an all-inclusive cartel, i.e., $m=n, D_{c}\left(x_{c}\right)$ is known prior to the auction $\left(D_{c}\left(x_{c}\right)=D(x)\right)$. In a partial cartel, i.e., $m<n, D_{c}\left(x_{c}\right)$ is only learned posterior to the auction. Although the immediate auction results (i.e., $l_{c}, D_{c}\left(l_{c}\right)$ and $D_{c}^{\prime}\left(l_{c}\right)=\hat{p}$ ) will provide the cartel with insufficient information to fully reconstruct the curve $D_{c}\left(x_{c}\right)$, I see no reason why the serious bidder, or any bidder for that matter, cannot request information on $D_{c}\left(x_{c}\right)$ from the auctioneer. If bidders are not entitled to request such information, the cartel can alternatively use a first-order (linear) approximation for $D_{c}^{\prime}\left(x_{c}\right)$.
} 
bidding procedure for determining how to allocate $l_{c}$ and $D_{c}\left(l_{c}\right)$ across cartel members (e.g., a knockout auction with a structure similar to the auction mechanism but for an inelastic supply) will necessary distort member's (ex-ante) incentives in communicating with the cartel mechanism.

Let us now look at the cartel's second problem that of enforcement with the cartel mechanism. Unlike in McAfee and McMillan (1992), the cartel in our multi-unit context is coalition proof in that it requires of no patience from its members to maintain cooperation through the official auction. The optimal deviation of bidder $j$, whether it is the serious bidder $(j=1)$ or any of the non-serious bidders $(j=2, \ldots, m)$, is to bid an empty demand schedule to the cartel mechanism (so as to reduce its residual supply curve at the official auction to the maximum extent possible) and then bid its true demand curve $P_{j}\left(x_{j}\right)$ at the official auction. But this deviation leaves the deviating bidder strictly worse off in an amount exactly equal to its share $\omega_{j}$ of the otherwise cartel profits.

\section{Final Remarks}

I have developed an auction mechanism for the optimal regulation of a commons resource (e.g., clean air, water stream, open fishery, etc.) when the regulator lacks information about the characteristics of the firms to be regulated. The mechanism is developed under the additional assumption that firms know nothing about other firms' characteristics. The mechanism is not only simple in that it is based on commonly used instruments (transferable licenses) but also remarkably effective in delivering the firstbest due to its VCG payoff structure. The mechanism yields the efficient allocation even when firms are acting collusively or when the aggregate supply of licenses is fixed. In addition, the mechanism provides firms with incentives to invest in socially optimal levels of R\&D.

One aspect that I leave for future research is the case in which a privately-informed agent is simultaneously on the demand and supply side of the auction. A (mandatory)

global carbon auction for dealing with climate change is a good example. Countries are on the demand side as polluting agents and on the supply side as recipients of pollution. Understanding that reducing pollution is a public good, the auction mechanism allocates pollution efficiently as long as there is no overlap of identities: polluters pay, at the margin, the Pigouvian price for their pollution licenses and recipients pay, at the margin, Lindahl prices for their pollution-reduction licenses. It is not obvious how to extend the auction mechanism when one or more agents are on both sides of the auction (and there are two or more agents on each side of the auction).

Another aspect not treated in the paper is the possibility that individual pollution (or resource use, more generally) cannot be perfectly monitored. In addition to the adverse selection problem of not observing a firm's type (e.g., abatement costs) the regulator must 
now overcome the moral hazard problem of not perfectly observing the firm's action. In a recent paper, Montero (2005) compares the performance of two instruments grandfathered transferable licenses and performance standards - in such information

environment. He finds that in some cases a standard-alone policy can welfare dominate a licenses-alone policy. In many cases, though, the optimal policy is to combine licenses and standards. It would be interesting to study how the auction mechanism extends to the case of imperfect monitoring and to ask whether and to what extent it remains (second-best) optimal to auctioning off the licenses together with a minimum performance standard.

\section{APPENDIX}

\section{PROOF OF PROPOSITION 1:}

Let $1>\omega_{i}>0$ be the fraction of licenses allocated to firm $i(=1, \ldots, n)$, so firm $i$ receives an initial allocation of $\omega_{i} l$, where $l$ is the total number of licenses and $\sum_{i=1}^{n} \omega_{i}=1$ (as commonly observed in practice, $\omega_{i}$ could be proportional to historic emissions, that is $\left.\omega_{i} \approx x_{i}^{0} / x^{0}\right)$. The license market is assumed perfectly competitive (i.e., $n$ large). Kwerel also requires $D^{\prime \prime}(x)>0$. Let $\bar{s}$ be the maximum value the subsidy can take, which by construction fixes the maximum number of licenses to $\bar{l}$, where $D^{\prime}(\bar{l})=\bar{s}$. The regulator sets $\bar{s}$ sufficiently high that is always above the first-best level $p^{*}$ for any possible realization of $P(x)$; otherwise, there is no point in using the scheme (in Kwerel (1977), $s$ is unbounded but in reality we cannot let it go to infinity).

We will demonstrate that the pair $(\bar{s}, \bar{l})$ is the unique Nash-equilibrium outcome of Kwerel's scheme when licenses are grandfathered. From the arguments in the text we do not need to consider the case of under-reporting. Thus, for a reported aggregate demand curve $\hat{P}(x) \geq P(x)$, the subsidy level is $s$ and the market price of licenses is $p=s$; hence, firm $i$ 's total compliance costs as a function of $s$ becomes

$$
T C_{i}(s)=C_{i}\left(X_{i}(s)\right)+s \cdot\left(X_{i}(s)-\omega_{i} l(s)\right)
$$

where $l(s)=D^{\prime-1}(s)$. The first term of (A1) is abatement cost and the second term is the net cost of purchasing licenses (which is negative when the firm is a net seller of licenses). Consider first the case in which the regulator sets $\bar{s}$ "close" to infinity. It is not difficult to see that no firm has incentives to move the outcome away from the pair $(\bar{s}, \bar{l})$. Since $X_{i}(s=\bar{s})=0$ for all $i=1$,..n (firms either shut down operations or install backstop zero-emission technologies), all firms become net sellers to the government and their total costs, $T C_{i}(s=\bar{s})=C_{i}(0)-\omega_{i} \bar{s} \bar{l}<0$, reach the minimum (recall that $\left.l^{\prime}(s)>0\right)$. Consequently, all firms will submit infinitely large demand curves $\hat{P}_{i}\left(x_{i}\right)$ so as to ensure that $s=\bar{s}$. 
Consider now the case in which $\bar{s}$ is not "extremely large" in the sense that for some or all firms $X_{i}(\bar{s})>0$. We have that

$$
\frac{d T C_{i}(s)}{d s}=C_{i}^{\prime} \cdot \frac{d X_{i}(s)}{d s}+X_{i}(s)-\omega_{i} l(s)+s \cdot\left(\frac{d X_{i}(s)}{d s}-\omega_{i} \frac{1}{D^{\prime \prime}(l(s))}\right)
$$

But $C_{i}^{\prime}=-s$, so evaluating $(\mathrm{A} 2)$ at $s=\bar{s}$ reduces to

$$
\left.\frac{d T C_{i}(s)}{d s}\right|_{s=\bar{s}}=X_{i}(\bar{s})-\omega_{i} l(\bar{s})-\frac{\omega_{i} \bar{s}}{D^{\prime \prime}(\bar{l})}
$$

Since over-reporting leads to $\sum_{i=1}^{n} X_{i}(\bar{s})<l(\bar{s})$, there must be a number of firms for which $d T C_{i}(\bar{s}) / d s<0$ (note that if firms are symmetric it is immediate that $d T C_{i}(\bar{s}) / d s<0$ for all firms; if firms are heterogeneous it may be still the case that $d T C_{i}(\bar{s}) / d s<0$ for all firms). Firms for which $d T C_{i}(\bar{s}) / d s<0$ have no incentives to move the outcome away from $s=\bar{s}$, hence, they will report $\hat{X}_{j}(p)=\infty$ for all $p \geq 0$, so as to ensure that $s=\bar{s}$. Firms for which $d T C_{j}(\bar{s}) / d s>0$, if any, cannot fully counterbalance these overreporting schedules because at best they can report $\hat{X}_{j}(p)=0$ for all $p \geq 0$. Therefore, the equilibrium outcome will necessarily be the pair $(\bar{s}, \bar{l})$.

\section{PROOF OF PROPOSITION 2:}

Let

$$
g(l)=\exp \int \frac{D^{\prime \prime}(l) l+D^{\prime}(l)}{D^{\prime}(l) l} d l=\exp \int d \ln \left(D^{\prime}(l) l\right)=D^{\prime}(l) l
$$

Then the solution to the differential equation (6) for $0 \leq l<\infty$ is given by

$$
\alpha(l)=\frac{1}{g(l)}\left(K+\int g(l) \frac{D^{\prime \prime}(l)}{D^{\prime}(l)} d l\right)=\frac{1}{D^{\prime}(l) l}\left(K+\int D^{\prime \prime}(l) l d l\right)
$$

where $K$ is an integration constant. Integrating by parts, we obtain

$$
\alpha(l)=\frac{1}{D^{\prime}(l) l}\left(K+D^{\prime}(l) l-D(l)\right)
$$

and setting the constant term $K$ to zero finishes the proof.

\section{PROOF OF PROPOSITION 3:}

It follows immediately from the construction of $\alpha_{i}\left(l_{i}\right)$ and Proposition 2 .

\section{PROOF OF PROPOSITION 4:}

Without any loss of generality let us parametrize firm $i$ 's inverse demand function as $P_{i}\left(x_{i}\right) \equiv P\left(x_{i}, \theta_{i}\right)$ where $\theta_{i}$ is an index of type and $\partial P / \partial \theta>0$ (similarly, the parametrization for the demand function is $X_{i}(p) \equiv X\left(p, \theta_{i}\right)$ where $\left.\partial X / \partial \theta>0\right)$. There is a one-to-one correspondence between a reported demand schedule $\hat{P}_{i}$ and a reported type $\hat{\theta}_{i}$. Consider for the moment only two firms, $i$ and $j$. The firms' reports $\hat{\theta}_{i}$ and $\hat{\theta}_{j}$ 
conducive to the most profitable collusive agreement are found by solving

$$
\left.\min _{\hat{\theta}_{i}, \hat{\theta}_{j}} C\left(x_{i}, \theta_{i}\right)+C\left(x_{j}, \theta_{j}\right)+\left[1-\alpha_{i}\left(l_{i}\left(\hat{\theta}_{i}, \hat{\theta}_{j}\right)\right)\right] \hat{p}\left(\hat{\theta}_{i}, \hat{\theta}_{j}\right) l_{i}\left(\hat{\theta}_{i}, \hat{\theta}_{j}\right)+\left[1-\alpha_{j}\left(l_{j}\left(\hat{\theta}_{i}, \hat{\theta}_{j}\right)\right)\right] \hat{p}\left(\hat{\theta}_{i}, \hat{\theta}_{j}\right) l_{j}\left(\hat{\theta}_{i}, \hat{\theta}_{j}\right)\right)
$$

subject to

$$
x_{i}+x_{j}=l_{i}\left(\hat{\theta}_{i}, \hat{\theta}_{j}\right)+l_{j}\left(\hat{\theta}_{i}, \hat{\theta}_{j}\right)=l\left(\hat{\theta}_{i}, \hat{\theta}_{j}\right)
$$

where $\hat{p}\left(\hat{\theta}_{i}, \hat{\theta}_{j}\right) \equiv \hat{p}$ is the auction clearing price as a function of firms' bids and $l_{i}\left(\hat{\theta}_{i}, \hat{\theta}_{j}\right) \equiv$ $l_{i}$ is the number of licenses allocated to firm $i$. In what follows I will omit $\hat{\theta}_{i}$ and $\hat{\theta}_{j}$ unless it would otherwise cause confusion. From Proposition 2 we know that

$$
\left[1-\alpha_{i}\left(l_{i}\right)\right] \hat{p} l_{i}=D_{i}\left(l_{i}\right)=\hat{p} l_{i}-\int_{\hat{p}_{j}\left(\hat{\theta}_{j}\right)}^{\hat{p}}\left[X^{s}(p)-X\left(p, \hat{\theta}_{j}\right)\right] d p
$$

where $X^{s}(p)$ is the social supply function, i.e., $D^{\prime}(x)$, so $X^{s}(p)-X\left(p, \hat{\theta}_{j}\right)$ is the residual supply faced by firm $i$, i.e., $D_{i}^{\prime}\left(x_{i}, \hat{\theta}_{j}\right)$; and $\hat{p}_{j}\left(\hat{\theta}_{j}\right) \leq \hat{p}$ is the (hypothetical) clearing price in the absence of firm $i$ 's bid (in terms of Figure $2, \hat{p}_{j}\left(\hat{\theta}_{j}\right)$ corresponds to $\left.\hat{p}_{-i}\right)$. The first-order condition for (A3) is (allowing for corner solutions)

$$
\frac{\partial C\left(x_{i}, \theta_{i}\right)}{\partial x_{i}} \frac{d x_{i}}{d l} \frac{\partial l}{\partial \hat{\theta}_{i}}+\frac{\partial C\left(x_{j}, \theta_{j}\right)}{\partial x_{i}} \frac{d x_{j}}{d l} \frac{\partial l}{\partial \hat{\theta}_{i}}+\frac{\partial D_{i}\left(l_{i}\right)}{\partial \hat{\theta}_{i}}+\frac{\partial D_{j}\left(l_{j}\right)}{\partial \hat{\theta}_{i}} \geq 0
$$

Recall that $-\partial C\left(x_{i}, \theta_{i}\right) / \partial x_{i}=P\left(x_{i}, \theta_{i}\right)$. To obtain an expression for $d x_{i} / d l$ use (A4) and note that collusion optima requires

$$
P\left(x_{i}, \theta_{i}\right)=P\left(x_{j}=l-x_{i}, \theta_{j}\right)=P\left(l, \theta_{i+j}\right)
$$

where $P\left(l, \theta_{i+j}\right)$ is the true aggregate demand function. Totally differentiating (A7) with respect to $l$ and rearranging leads to

$$
\frac{d x_{i}}{d l}=\frac{P_{j}^{\prime}}{P_{i}^{\prime}+P_{j}^{\prime}}
$$

where $P_{i}^{\prime} \equiv \partial P\left(x_{i}, \theta_{i}\right) / \partial x_{i}$. To obtain expressions for $\partial D_{i}\left(l_{i}\right) / \partial \hat{\theta}_{i}$ and $\partial D_{j}\left(l_{j}\right) / \partial \hat{\theta}_{i}$ (or $\left.\partial D_{i}\left(l_{i}\right) / \partial \hat{\theta}_{j}\right)$, on the other hand, note that from (A5) we have

$$
\frac{\partial D_{i}\left(l_{i}\right)}{\partial \hat{\theta}_{i}}=\frac{\partial \hat{p}}{\partial \hat{\theta}_{i}} l_{i}+\hat{p} \frac{\partial l_{i}}{\hat{\theta}_{i}}-\frac{\partial \hat{p}}{\partial \hat{\theta}_{i}}\left[X^{s}(\hat{p})-X\left(\hat{p}, \hat{\theta}_{j}\right)\right]
$$


But $X^{s}(\hat{p})-X\left(\hat{p}, \hat{\theta}_{j}\right)=l_{i}$, so $(\mathrm{A} 9)$ reduces to

$$
\frac{\partial D_{i}\left(l_{i}\right)}{\partial \hat{\theta}_{i}}=\hat{p} \frac{\partial l_{i}}{\hat{\theta}_{i}}
$$

Similarly,

$$
\frac{\partial D_{i}\left(l_{i}\right)}{\partial \hat{\theta}_{j}}=\frac{\partial \hat{p}}{\partial \hat{\theta}_{j}} l_{i}+\hat{p} \frac{\partial l_{i}}{\hat{\theta}_{j}}-\frac{\partial \hat{p}}{\partial \hat{\theta}_{j}} l_{i}+\frac{\partial \hat{p}_{j}\left(\hat{\theta}_{j}\right)}{\partial \hat{\theta}_{j}} \cdot 0+\int_{\hat{p}_{j}}^{\hat{p}} \frac{\partial X\left(p, \hat{\theta}_{j}\right)}{\partial \hat{\theta}_{j}} d p
$$

Rearranging and inverting $i$ by $j$ leads to

$$
\frac{\partial D_{j}\left(l_{j}\right)}{\partial \hat{\theta}_{i}}=\hat{p} \frac{\partial l_{j}}{\partial \hat{\theta}_{i}}+\int_{\hat{p}_{i}}^{\hat{p}} \frac{\partial X\left(p, \hat{\theta}_{i}\right)}{\partial \hat{\theta}_{i}} d p
$$

Note that since $\hat{p}_{i} \leq \hat{p}$ the last term of (A11) is non-negative. Plugging (A8), (A10) and (A11) into (A6), using (A7) and rearranging, the two first-order conditions become

$$
\frac{\partial l\left(\hat{\theta}_{i}, \hat{\theta}_{j}\right)}{\partial \hat{\theta}_{i}}\left[-P\left(l\left(\hat{\theta}_{i}, \hat{\theta}_{j}\right), \theta_{i+j}\right)+\hat{p}\left(\hat{\theta}_{i}, \hat{\theta}_{j}\right)\right]+\int_{\hat{p}_{i}\left(\hat{\theta}_{i}\right)}^{\hat{p}\left(\hat{\theta}_{i}, \hat{\theta}_{j}\right)} \frac{\partial X\left(p, \hat{\theta}_{i}\right)}{\partial \hat{\theta}_{i}} d p \geq 0 \quad \text { for } i \text { and } j
$$

By inspection of (A12) one arrives at two possible solutions. One solution is for $i$ to report $\hat{\theta}_{i}=\theta_{i+j}$ (i.e., the true aggregate demand curve) and for $j$ to report the corner $\hat{\theta}_{j}=\emptyset$ (i.e., $\hat{X}_{j}=0$ for all $p$ ). If so, $P\left(l, \theta_{i+j}\right)=\hat{p}=\hat{p}_{i}>\hat{p}_{j}=D^{\prime}(0)$, and hence, the first-order condition for $i$ equals to zero and the first-order condition for $j$ is strictly positive. The second solution is just the inverse. Both solutions are equally optimal (for the firms) and, more importantly, they implement the first-best in that firms find it in their best collusive interest to submit the aggregate true curve. Extending the proof to the case of more than two firms and to the possibility of partial collusion (i.e., collusion among a subset of firms) is straightforward.

\section{PROOF OF PROPOSITION 5:}

Given members' obedience to the cartel mechanism for whatever demand schedules they choose to report, cartel member $j=1, \ldots, m \leq n$ will report the demand schedule $\tilde{P}_{j}(\cdot)$ that solves (recall the one-to-one correspondence between reporting $\tilde{P}_{j}(\cdot)$ and requesting $l_{j}$ licenses)

$$
\min _{l_{j}} C_{j}\left(l_{j}\right)+D_{j}\left(l_{j}\right)-\omega_{j}\left(\sum_{k=1}^{m} D_{k}\left(l_{k}\left(l_{j}\right)\right)-D_{c}\left(l_{c}\right)\right)
$$

where $l_{k}\left(l_{j}\right)$ is member $k$ 's license allocation as a function of $j$ 's allocation and $l_{c}=$ 
$\sum_{k=1}^{m} l_{k}$. The first-order condition is

$$
C_{j}^{\prime}\left(l_{j}\right)+D_{j}^{\prime}\left(l_{j}\right)-\omega_{j}\left(\sum_{k=1}^{m}\left(D_{k}^{\prime}\left(l_{k}\right)-D_{c}^{\prime}\left(l_{c}\right)\right) \frac{d l_{k}}{d l_{j}}\right)=0
$$

But from the auction clearing condition we have $\hat{p}=D_{c}^{\prime}\left(l_{c}\right)=D_{k}^{\prime}\left(l_{k}\right)$ for all $k=1, \ldots, m$, which finishes the proof.

\section{REFERENCES}

Ausubel, Lawrence M. 2004. "An Efficient Ascending-Bid Auction for Multiple Objects." American Economic Review, 94(5): 1452-75.

Biglaiser, Gary, John K. Horowitz, and John Quiggin. 1995. "Dynamic Pollution Regulation." Journal of Regulatory Economics, 8(1): 33-44.

Bovenberg, A. Lans, and Lawrence H. Goulder. 1996. "Optimal Environmental Taxation in the Presence of Other Taxes: General Equilibrium Analysis." American Economic Review, 86(4): 985-1000.

Caffera, Marcelo, and Juan Dubra. 2006. "Getting Polluters to Tell the Truth." Universidad de Montevideo, Department of Economics, Working Paper.

Cramton, Peter, and Suzi Kerr. 2002. "Tradeable Carbon Permit Auctions: How and why to Auction not Grandfather." Energy Policy, 30(4): 333-45.

Dasgupta, Partha, Peter Hammond, and Eric Maskin. 1980. "On Imperfect Information and Optimal Pollution Control." Review of Economic Studies, 47(5): 857-60.

Duggan, John, and Joanne Roberts. 2002. "Implementing the Efficient Allocation of Pollution." American Economic Review, 92(4): 1070-78.

Gersbach, Hans, and Till Requate. 2004. "Emission Taxes and Optimal Refunding Schemes." Journal of Public Economics, 88(3-4): 713-25.

Green, Jerry R. and Laffont, Jean-Jacques. 1979. Incentives in Public Decision Making. Amsterdam: North-Holland.

Joskow, Paul L., Richard Schmalensee, and Elizabeth M. Bailey. 1998. "The Market for Sulfur Dioxide Emissions." American Economic Review, 88(4): 669-85.

Kim, Jae-Cheol, and Ki-Bok Chang. 1993. "An Optimal Tax/Subsidy for Output and Pollution Control under Asymmetric Information in Oligopoly Markets." Journal of Regulatory Economics, 5(2): 183-97.

Klemperer, Paul. 2004. Auctions: Theory and Practice. Princeton: Princeton University Press.

Kremer, Ilan, and Kjell G. Nyborg. 2004. "Divisible-Good Auctions: The Role of Allocation Rules." RAND Journal of Economics, 35(1): 147-59. 
Kwerel, Evan. 1977. "To Tell the Truth: Imperfect Information and Optimal Pollution Control." Review of Economic Studies, 44(3): 595-601.

Laffont, Jean-Jacques, and Jean Tirole. 1996. "Pollution Permits and Environmental Innovation." Journal of Public Economics, 62(1-2): 127-40.

Mas-Colell, Andreu, Michael D. Whinston, and Jerry R. Green. 1995. Microeconomics Theory. Oxford: Oxford University Press.

McAdams, David. 2005. "Adjustable Supply in Uniform Price Auctions: The Value of Non-Commitment." MIT, Sloan School of Management, Working Paper No. 4522-05.

McAfee, R. Preston, and John McMillan. 1992. "Bidding Rings." American Economic Review, 82(3): 579-99.

Milgrom, Paul. 2004. Putting Auction Theory to Work. Cambridge: Cambridge University Press.

Montero, Juan-Pablo. 2005. "Pollution Markets with Imperfectly Observed Emissions." RAND Journal of Economics, 36(3): 645-60.

Montero, Juan-Pablo. 2007. "A Simple Auction Mechanism for the Optimal Allocation of the Commons: Some Extensions." Cuadernos de Economia, forthcoming.

Roberts, Marc J., and Michael Spence. 1976. "Effluent Charges and Licenses under Uncertainty." Journal of Public Economics, 5(3-4): 193-208.

Spulber, Daniel F. 1988. "Optimal Environmental Regulation under Asymmetric Information." Journal of Public Economics, 35(2): 163-81.

Stavins, Robert N. 2003. "Experience with Market-Based Environmental Policy Instruments." In Handbook of Environmental Economics. Vol. 1, ed. Karl-Göran Mäler and Jeffrey Vincent, 355-435. Amsterdam: Elsevier Science.

Tietenberg, Tom. 2003. "The Tradable-Permits Approach to Protecting the Commons: Lessons for Climate Change." Oxford Review of Economics Policy , 19(3): 400-19.

Varian, Hal R. 1994. "A Solution to the Problem of Externalities when Agents are Well-Informed." American Economic Review, 84(5): 1278-93.

Vickrey, William. 1961. "Counterspeculation, Auctions and Competitive Sealed Tenders." Journal of Finance, 16(1): 8-37.

Weitzman, Martin L. 1974. "Prices vs. Quantities." Review of Economic Studies, 41(4): 477-91.

Wiggins, Steven N., and Gary D. Libecap. 1985. "Oil Field Unitization: Contractual Failure in the Presence of Imperfect Information." American Economic Review, 75(3): 368-85.

Wilson, Robert. 1979. "Auctions of Shares." Quarterly Journal of Economics, 93(4): 675-89. 


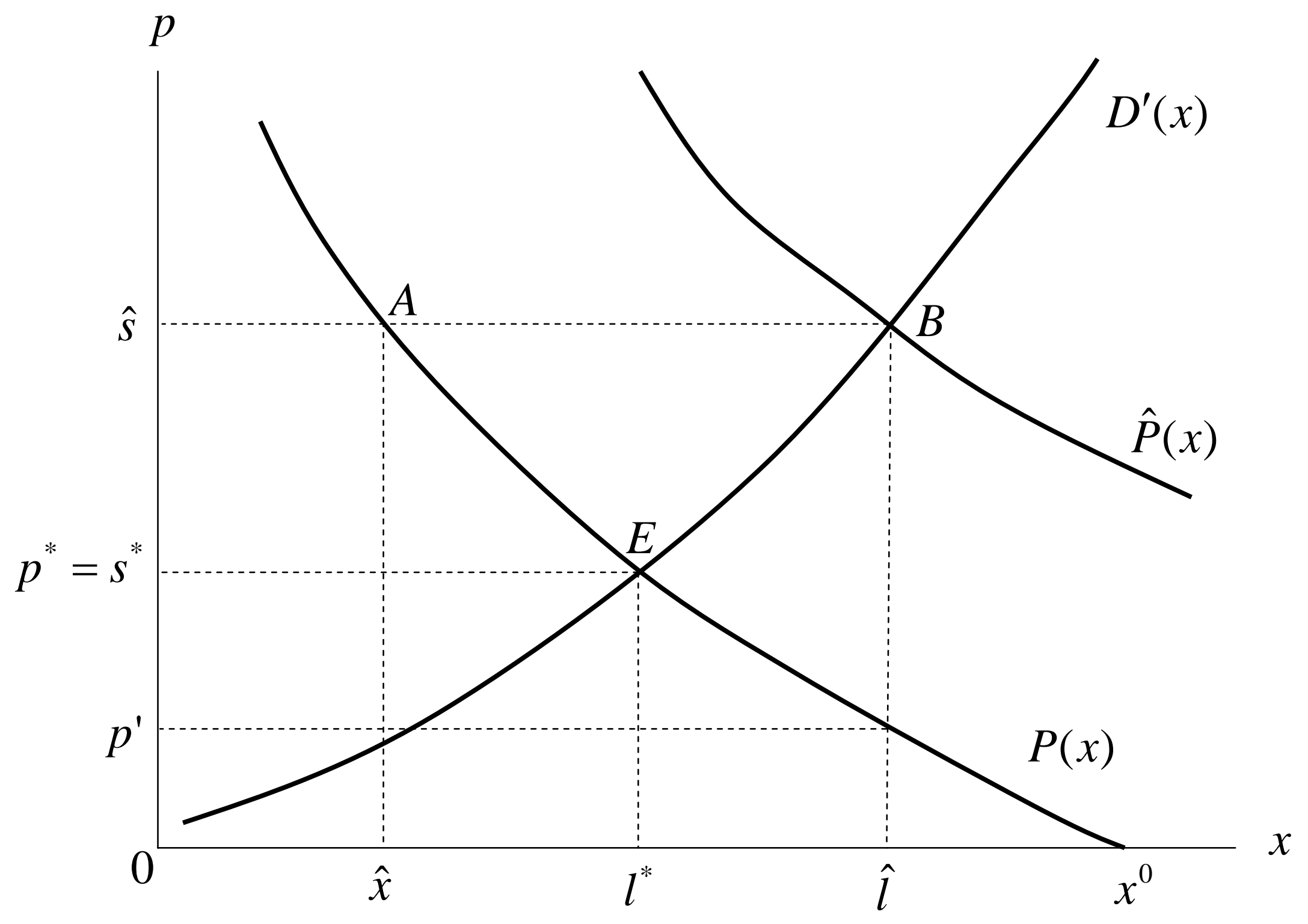

Figure 1a: Incentives to over-report 


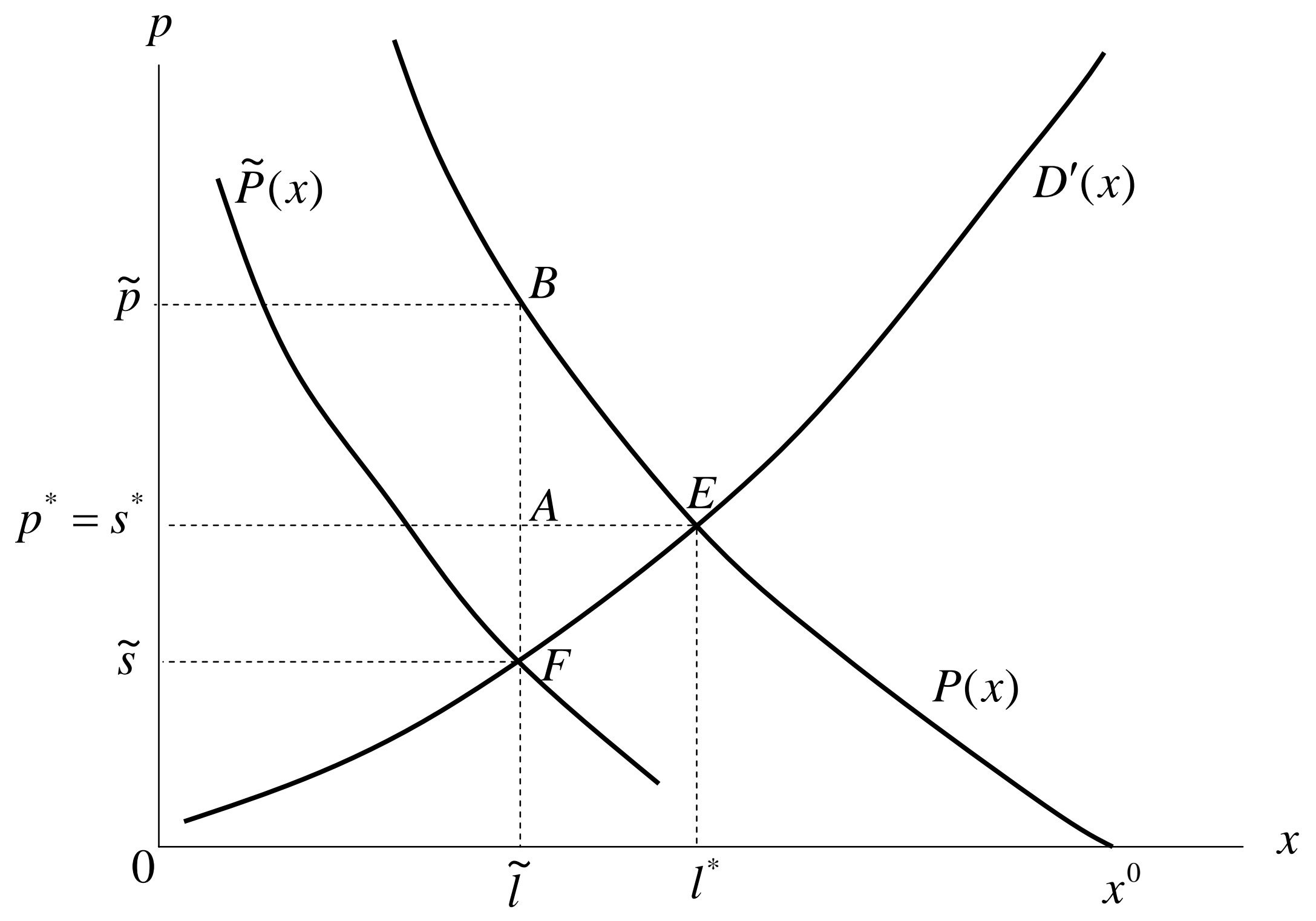

Figure 1b: Incentives to under-report 


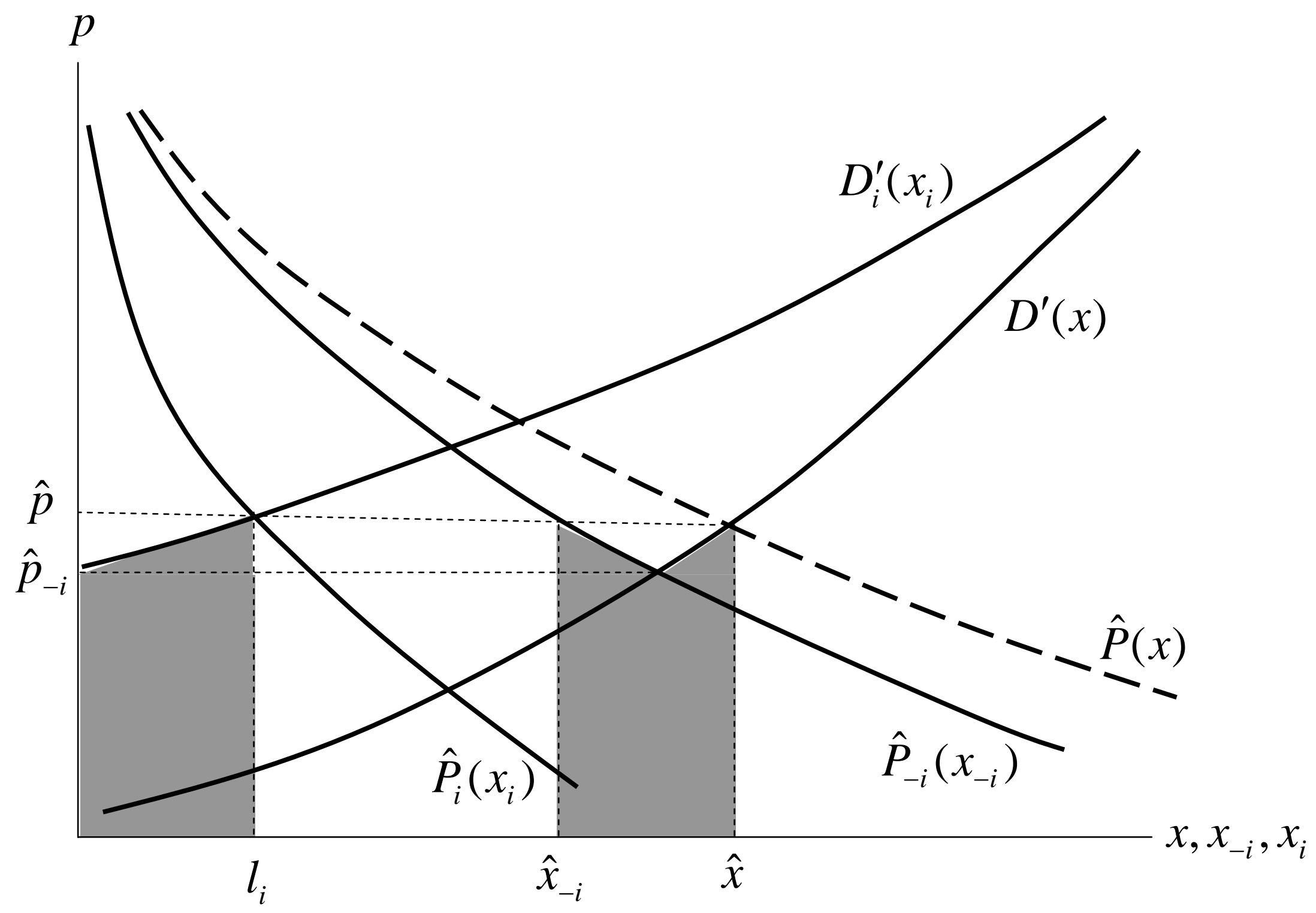

Figure 2: Residual supply (i.e., marginal damage ) function 


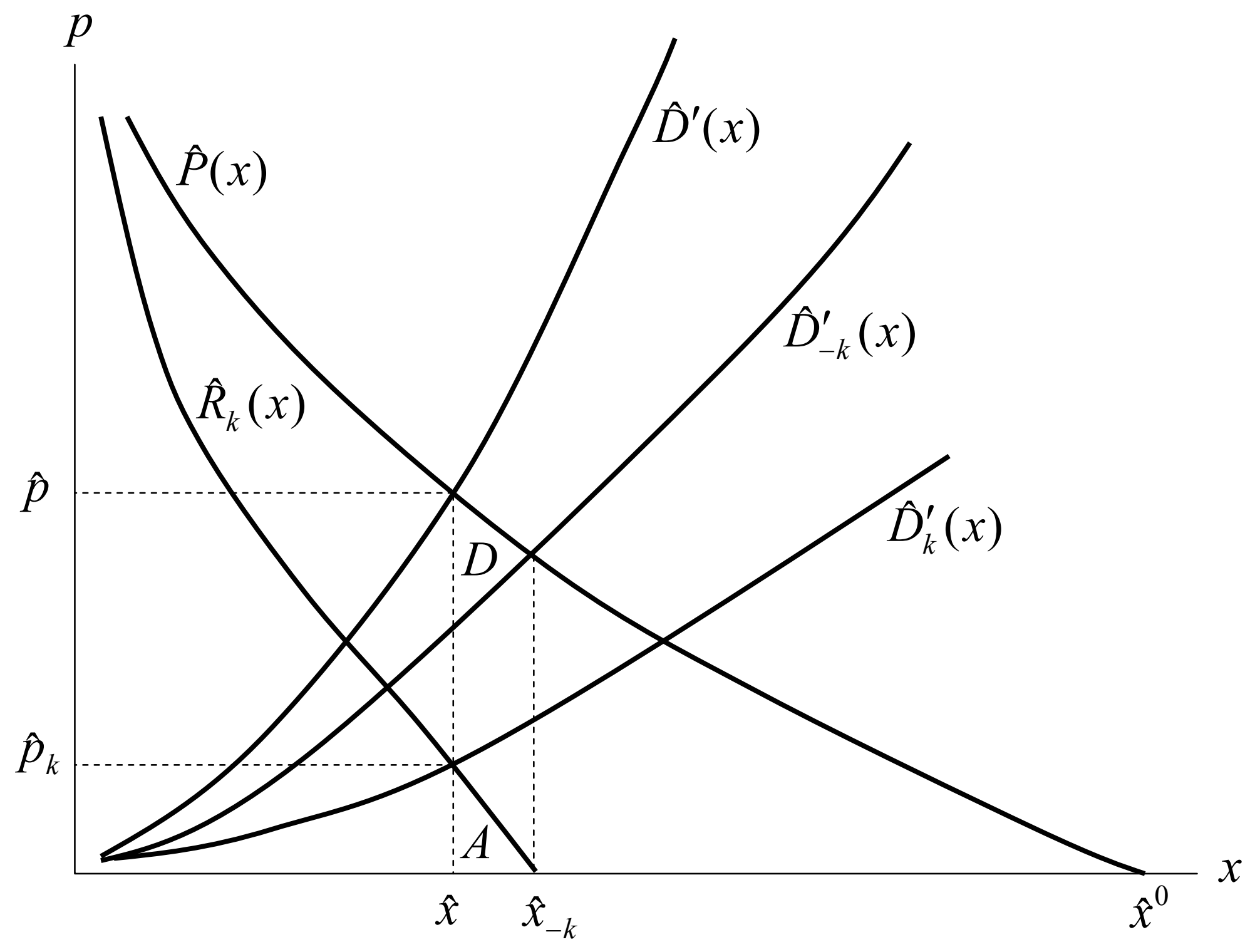

Figure 3: Asymmetric information on the supply side 